\title{
THE MOLECULAR FORMS OF GDF9 IN A RANGE OF MAMMALIAN SPECIES
}

\begin{abstract}
Abdulaziz Abdulnasser Alhussini
A thesis submitted to the Victoria University of Wellington in partial fulfillment of the requirements for the degree of Masters in Biomedical Science
\end{abstract}

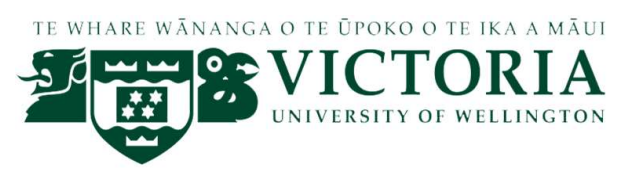

Victoria University of Wellington

Te Whare Wānanga o te Ūpoko o te Ika a Mãui 


\section{Table of Contents}

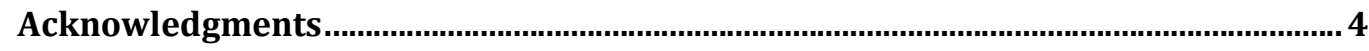

Abstract

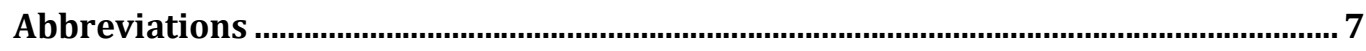

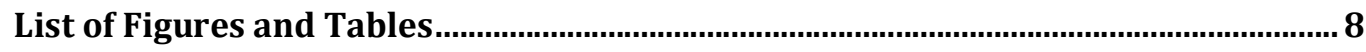

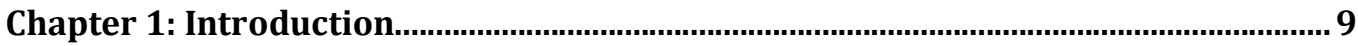

1.1 The Transforming Growth Factor- Beta Superfamily …................................................... 9

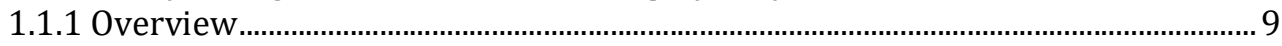

1.1.2 Structure ................................................................................................................ 10

1.1.3 TGF $\beta$ Receptors and Secondary Messenger Signaling Pathways........................ 11

1.2 Growth Differentiation Factor 9 and Bone Morphogenetic Protein 15..........................13

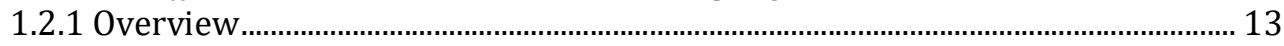

1.2.2 Mutations and Immunization Studies …….......................................................... 15

1.2.3 Structural Characteristics................................................................................. 17

1.2.4 Receptors and Signaling ................................................................................ 18

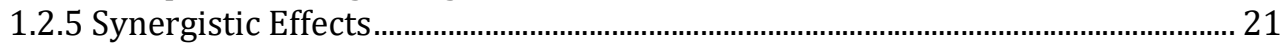

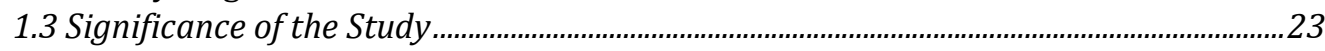

1.4 Aims

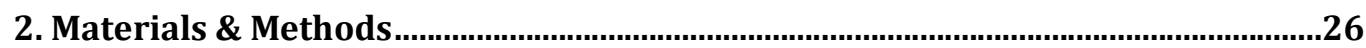

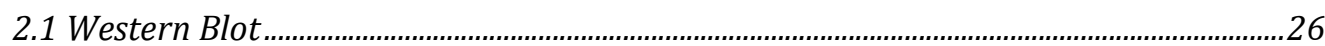

2.1.1 Sample collection for western blots ........................................................................ 26

2.1.2 Positive and negative control samples................................................................. 28

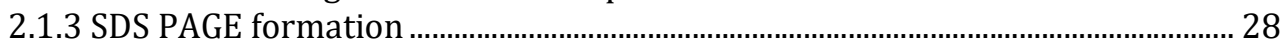

2.1.4 Sample preparation.............................................................................................. 28

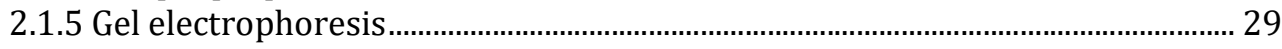

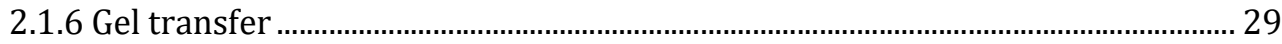

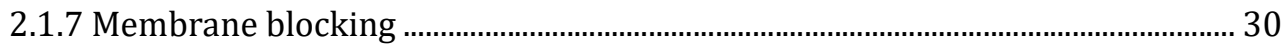

2.1.8 The primary antibody incubating conditions......................................................... 30

2.1.9 Secondary antibody incubation ......................................................................... 30

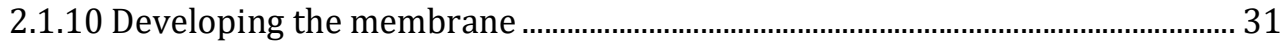

2.1.11 Determining exposure length.......................................................................... 31

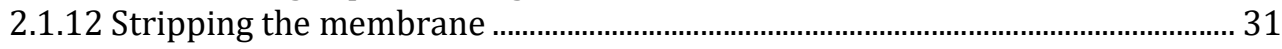

2.1.13 Calculating band size .......................................................................................... 32

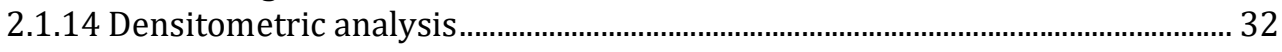

2.2 Methyl-3H-thymidine uptake bioassay ………...................................................................33

2.2.1 Sample collection ……………..................................................................................... 33

2.2.2 Cell counting............................................................................................................ 33

2.2.3 Testing the ability of the GDF9 and BMP15 monoclonal antibodies to recognise biologically-active forms of GDF9 and BMP15........................................... 34

2.2.4 Harvesting and methyl- ${ }^{3} \mathrm{H}$-thymidine uptake measurement ............................... 35

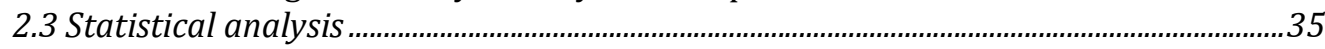

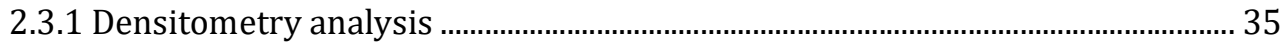

2.3.2 Methyl- ${ }^{3} \mathrm{H}$-thymidine uptake............................................................................. 35

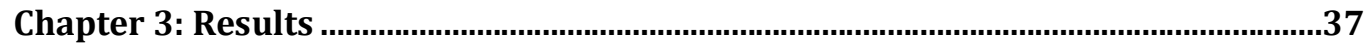

3.1 Estimation of the concentration of recombinant pig mature GDF9 conditioned media

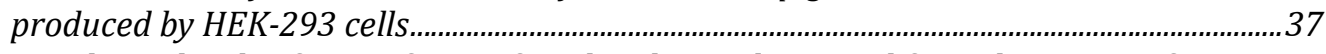

3.2 The molecular forms of GDF9 found within and secreted from the oocyte of mammalian species.

3.2.1 Rats (litter size 7-16).......................................................................................... 39

3.2.2 Pigs (litter size 14-22)......................................................................................... 40 


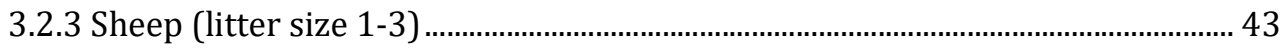

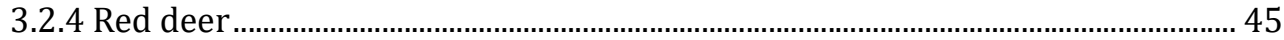

3.3 Species comparisons of molecular forms of GDF9.............................................................4

3.4 Quantification of molecular forms of GDF9 across four mammalian species................50

3.5 Comparison between the antibodies MAB37A and MAB37G in identifying GDF9

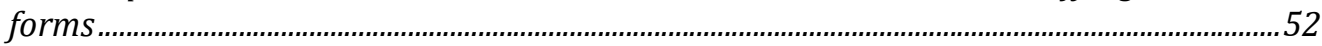

3.6 Comparison between GDF9 and BMP15 molecular forms found within the oocyte

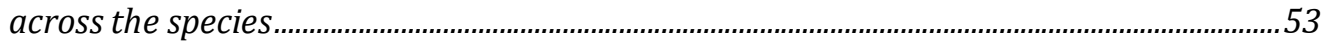

3.7 Bioactivity of recombinant pig GDF9 to BMP15 .................................................................54 3.8 Neutralisation of the bioactivity of recombinant pig GDF9 to BMP15 using GDF9 and

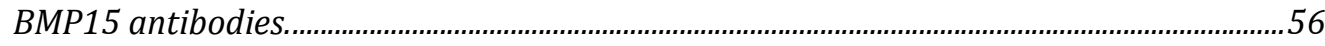

Chapter 4: Discussion ......................................................................................................59

4.1: The molecular forms of GDF9 present within or secreted from oocyte of different mammalian species with different litter sizes (rat, pig, sheep, and red deer).......................59 4.2: The relative amount of promature and mature GDF9 found within or secreted from oocytes of different mammalian species with different litter size (rat, pig, sheep, and red deer)... 63 4.3: The ability of the monoclonal antibodies to bind biologically-active GDF9 or BMP15

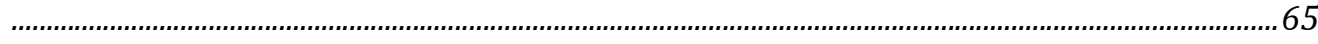

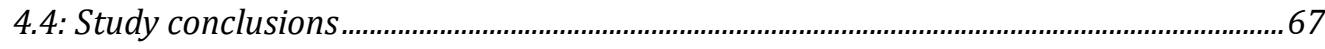

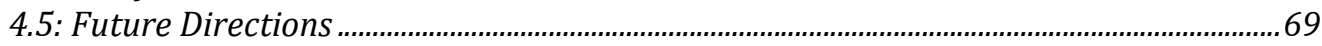

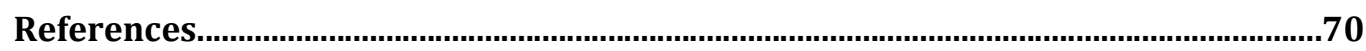

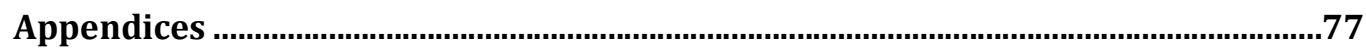

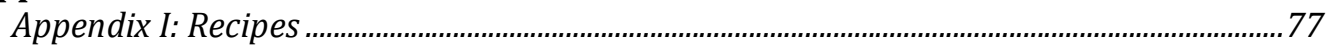

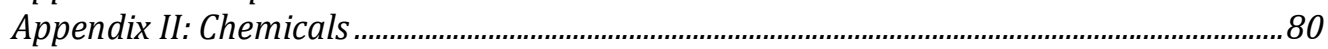

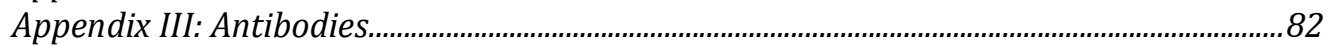




\section{Acknowledgments}

Firstly, I would like to thank my supervisor, Dr. Janet Pitman, for accepting me, giving me the opportunity to work in her research group, the time dedication and the huge support she provided the whole time during my master degree starting from experiment planning till thesis writing. Also, I would like to thank Dr. Ken McNatty, Dr. Derek Heath, Adrian Bibby, Sarah Sczelecki, and Dr. Shalen Kumar for sharing their knowledge, expertise and support in the lab by either answering questions or help in troubleshooting an experiment. I am grateful for being part of the reproduction group at Victoria University of Wellington, as they provided continuous support, help, encouragement, and creating a lovely working environment that make you feel welcomed instantly.

Thank you to the Department of Psychology at Victoria University of Wellington; the Taylor Preston meat processing plant in Ngauranga, Wellington; the Venison Packers Feilding Ltd meat processing plant in Fielding; and Cabernet Foods, Kintyre Meats Ltd in Gladstone for providing access to the ovaries required for this research, and for being friendly and helpful.

I would like to acknowledge funding support from the Royal Society of New Zealand Marsden fund (Contract13-VUW-153) for funding that research.

I would like to express my appreciation to my country, particularly King Abdullah bin Abdulaziz scholarship program for supporting me during my study by providing me with a scholarship during my education journey.

Finally, I would to thank my father, mother, wife, brothers, sisters, and friends for their help, support, and alleviating stress when it was needed. This journey would not be the same without your support. 


\section{Abstract}

Growth Differentiation Factor (GDF) 9 is a member of the transforming growth factor $\beta$ (TGF $\beta$ ) superfamily that is exclusively expressed within and secreted from, the oocyte. This protein has generated much interest as it has been found to play a major role in follicular growth and maturation in mammals, and may be involved in determining litter size. Like most TGF $\beta$ family members, it is synthesised as a pre-pro-mature protein and is cleaved at various stages to allow the biologically active mature form to bind its Type II receptor. The aim of this study was to improve our understanding of the different molecular forms of GDF9 that are present within ovarian follicles of a range of mammalian species that differ in litter size. To achieve this aim, Western blotting experiments were performed to illustrate the molecular forms that were present within, and secreted from, the oocytes of rats, pigs, sheep and red deer. The detection of bands that represented the different molecular forms of GDF9 was undertaken using a monoclonal antibody that targeted a conserved region in the mature form of ovine GDF9.

The predominant forms of GDF9 found within and secreted from the oocyte across the species were the promature and cleaved mature forms of GDF9. Densitometry analysis of the Western blots revealed that pig, sheep, and red deer had significantly more of the promature, than the mature, form within the oocyte. Conversely, there were no significant differences between the levels of promature and mature forms of GDF9 in the secreted media. Moreover, the levels of the specific molecular forms of GDF9 were not different between pigs, sheep and red deer. The levels of GDF9 in rat samples were low which may be due to a lower affinity of the monoclonal GDF9 antibody due to sequence differences between rat and ovine GDF9.

Interestingly, applying a crosslinking reagent to the oocyte lysate and conditioned media samples revealed the appearance of a high molecular size 
band. The appearance of this band, which was more prominent in the rat and pig, was concomitant with the disappearance of the mature GDF9 band. The differential levels of these presumptive GDF9 multimers in these two species that have large litters may suggest that rat and pig mature GDF9 binds other oocyte secreted factors more readily than GDF9 from mono-ovulatory species.

Importantly, no homo- or hetero- mature dimers of GDF9 were detected in any of the species studied.

In summary, GDF9 was predominantly present as promature and cleaved mature forms both within the oocyte and in the secretions from the oocyte. Overall, these results indicated that the promature form was present in higher levels than the cleaved mature form. With the exception of the rat, there were no detectable species differences in the levels of the GDF9 forms within or secreted from the oocyte using Western blotting methodologies. 


\begin{tabular}{|c|c|}
\hline ActRII & Activin receptor type II \\
\hline ALK & Activin receptor-Like Kinases \\
\hline $\mathrm{AMH}$ & Anti-Mullerian Hormone \\
\hline ANOVA & Analysis of Variance \\
\hline BMP & Bone Morphogenetic Protein \\
\hline BMPRII & Bone Morphogenetic Protein Receptor type II \\
\hline $\mathrm{bp}$ & base pair \\
\hline cDNA & cloned Deoxyribonucleic Acid \\
\hline CI & Confidence Interval \\
\hline CM & Conditioned Media \\
\hline $\mathrm{COC}$ & Cumulus cell-Oocyte Complexes \\
\hline E.coli & Escherichia coli \\
\hline FSH & Follicle Stimulating Hormone \\
\hline GC & Granulosa Cell \\
\hline GDF & Growth Differentiation Factor \\
\hline HEK293 & Human Embryonic Kidney 293 cell \\
\hline HRP & Horseradish Peroxidase \\
\hline $\operatorname{IgG}$ & Immunoglobulin G \\
\hline IVF & In Vitro Fertilisation \\
\hline IVM & In Vitro Maturation \\
\hline $\mathrm{kDa}$ & kilo Dalton \\
\hline KO & Knocked Out \\
\hline MAB & Monoclonal Antibody \\
\hline mRNA & messenger Ribonucleic Acid \\
\hline $\mathrm{R}^{2}$ & Coefficient of Determination \\
\hline SDS & Sodium Dodecyl Sulfate \\
\hline SDS-PAGE & Sodium Dodecyl Sulfate Polyacrylamide Gel Electroporesis \\
\hline \multirow[t]{2}{*}{ SMADs } & Similar to mothers against decapentaplegic (MAD) and the \\
\hline & Caenrhabditis elegans protein small (SMA) \\
\hline TGF $\beta$ & Transforming Growth Factor $\beta$ \\
\hline TGF $\beta$ RII & Transforming Growth Factor $\beta$ Receptor type II \\
\hline
\end{tabular}




\section{List of Figures and Tables}

Figure 1.1: $\quad$ Alignment of the GDF9 amino acid sequence ............................. 19

Figure 3.1: $\quad$ Estimation of the pig mature GDF9 produced by HEK293 ............. 38

Figure 3.2: GDF9 molecular forms found within and secreted from rat oocyte 40

Figure 3.3: GDF9 molecular forms found within and secreted from pig oocyte

Figure 3.4: GDF9 molecular forms found within and secreted from sheep oocyte

Figure 3.5: GDF9 molecular forms found within and secreted from red deer oocyte 46

Figure 3.6: Alignment of GDF9 molecular forms found within and secreted from different litter size mammalian species

Figure 3.7: Densitometry analysis of GDF9 molecular form in different litter size mammalian species

Figure 3.8: Comparison between MAB37A and MAB37G 52

Figure 3.9: Comparison between GDF9 and BMP15 molecular forms found within oocyte of different litter size mammalian species

Figure 3.10: The effect of adding GDF9 and BMP15 pig recombinant on sheep granulosa cells

Figure 3.11: The effect of adding different ratios of GDF9 to BMP15 pig recombinant on sheep granulosa cells 55

Figure 3.12: Neutralising bioactive pig GDF9 or pig BMP15 recombinant using MAB

Table 1: A summary of the observed and the molecular sizes of the forms of GDF9 under different conditions identified across the studied species 


\section{Chapter 1: Introduction}

\subsection{The Transforming Growth Factor- Beta Superfamily}

\subsubsection{Overview}

The transforming growth factor $\beta$ (TGF $\beta$ ) superfamily coordinates developmental processes in many organisms and there are over 35 protein members in mammals (Mueller \& Nickel, 2012). Genome sequence information reveals that TGF $\beta$ genes common ancestor goes back to metazoan, which evolved to be more complex and specific in mammals (Massagué, 2012, Mueller \& Nickel, 2012, Macias et al., 2015). The TGF $\beta$ superfamily is comprised of four major subgroups, namely the activins/inhibins, growth differentiation factors (GDF), bone morphogenetic proteins (BMP), and a diverse group containing TGF $\beta$ and anti-mullerian hormone (AMH). These subgroups share a common structural motif with high homology across their amino acid sequence (Shimasaki et al., 2004, Juengel \& McNatty, 2005).

The members of the TGF $\beta$ superfamily generally regulate growth, differentiation, and apoptosis in a wide range of cells (Miettinen, 1994, Juengel et al., 2004, Juengel \& McNatty, 2005). The TGF $\beta$ 1, 2 and 3 proteins are located in granulosa and thecal cells, and are critical for luteinisation and proliferation of granulosa cells. In addition, TGF $\beta$ proteins are known for their pleiotropic potency, which allow them to play role in embryo development and progression of cancer (Mueller \& Nickel, 2012, Macias et al., 2015). Previously it was thought that only the endocrine system was capable of having a multi-functional purpose (Macias et al., 2015). However, several members of the TGF $\beta$ superfamily have different functions in different cell types. For example, gonad-derived activin regulates the expression and secretion of pituitary gland-derived FSH (Mueller \& Nickel, 2012). On the other hand, activin, also induces the mesoderm, which is important for organogenesis, and has a role in inflammation and immunity, where these functions are occurring (taking place) outside the gonads (Mueller \& 
Nickel, 2012). Similarly, BMP7 has been found to play roles in skeletogenesis, eye and heart development and neurogenesis (Mueller \& Nickel, 2012). On the other hand, some members are known to be exclusive to specific cell types. For example, GDF9 and BMP15 are found in only in the ovarian follicle (Juengel \& McNatty, 2005).

\subsubsection{Structure}

Members of the TGF $\beta$ superfamily are synthesised as preproproteins consisting of a signal peptide, a large proregion, and a biologically-active mature region that is small in size (Jakowlew et al., 1988,Ozkaynak et al., 1990, Juengel \& McNatty, 2005, Shi et al., 2011, Mueller \& Nickel, 2012). The proregion is traditionally known for its regulatory function; that is to ensure correct folding and dimerisation, as well as inhibiting or activating protein function, and these roles differ between the members of the family (Juengel \& McNatty, 2005). It is proposed that the different biological functions of the proregions are due to variability in the amino acid sequence across the members of the TGF $\beta$ superfamily (Mueller \& Nickel, 2012). Moreover, the solubility of the proregion in physiological conditions aids protein transportation by diffusion; in comparison, the mature region has poor solubility in similar conditions (Mueller \& Nickel, 2012).

The mature region is separated from the larger structure at a basic amino acid cleavage site; usually a four amino acid sequence that starts and ends with arginine (RXXR) and is recognised by proprotein convertase family members, such as furin (Ozkaynak et al., 1990, Juengel \& McNatty, 2005). A study of the crystallography structure of BMP7 in comparison to TGF $\beta 2$ indicated high similarity of their primary folding, with the conservation of the cysteines, despite the sequence homology being considered low (Griffith et al., 1996). The general structure of the monomer is comprised of two pairs of antiparallel $\beta$-sheets projecting away from the general $\alpha$-helix. This structure is similar across many different members of the superfamily including BMP7, GDF5, activin, TGF $\beta 1$, TGF $\beta 2$, and TGF $\beta 3$ (Lin et al., 2006). The cysteine knot that forms between six 
of the seven or nine conserved cysteines in the mature region is another feature of this protein family. The knot is comprised of a disulfide bond in the core that crosses the ring formed by two other disulfide bonds (Lin et al., 2006, Shi et al., 2011). Also, the cysteine knot is characterised by a stop codon following the last cysteine to allow the butterfly shape to form. Therefore the addition of a c-tag to one of these proteins would disturb that structure (Mueller \& Nickel, 2012).

Another characteristic of this superfamily is that these proteins form homo- or hetero-dimers through the covalent binding of another conserved cysteine residue to form a disulfide bridge, where the active form is stabilised by hydrophobic interactions (Juengel \& McNatty, 2005, Lin et al., 2006). On the other hand, one theory suggests that the variability in the proregion across the TGF $\beta$ members would not allow the stabilisation of the hetero-dimer, though it has been reported in zebrafish and recombinant forms of BMP2/6 and BMP4/7 (Mueller \& Nickel, 2012).

\subsubsection{TGF $\beta$ Receptors and Secondary Messenger Signaling Pathways}

The signaling pathway utilised by the TGF $\beta$ ligands is transmitted through a composition of two types of membrane bound serine-threonine kinases (Shimasaki et al., 2004, Juengel \& McNatty, 2005). To date, there has been identification of seven type I receptors; which are known as activin receptor-like kinases (ALK) 1-7, and five type II receptors ActRII, ActRIIB, BMPRII, TGF $\beta$ RII and AMHRII (Shimasaki et al., 2004, Juengel \& McNatty, 2005). Through various TGF $\beta$-resistant mutant cell lines, where the ligands either failed to bind or transmit signal if type I or type II receptors is mutated, it was discovered that a heteromeric receptor complex is required to transmit the signal of the TGF $\beta$ protein (Wrana et al., 1992). Thus, the binding of the ligand to the type I receptor requires the binding to the type II receptor also. The signaling is not initiated by the binding of type II receptor only; therefore there is an interdependence of these receptors to transmit the signal (Wrana et al., 1992). The possible combinations that could arise between the seven type I receptors, and the five type II receptors raises a large number of unique receptor complexes with 
specific signaling characteristics (Juengel \& McNatty, 2005). The affinity of the ligand for a receptor differs among the different members of the TGF $\beta$ superfamily. For example, some have a higher affinity towards type II receptors, such as TGF $\beta$, activin, and others have a higher affinity towards type I receptors, such as the BMP group (Juengel \& McNatty, 2005). It remains unclear how the heteromeric receptor dimer is formed. Some theories suggest that ligands with high affinity to type I receptor will be bound at the ligand's concave surface, whereas the ligands with higher type II affinity will be bound at the ligand's convex surface (Lin et al., 2006). Other theories suggest an allosteric effect whereby some ligands might undergo conformational changes to bind to the type II receptor that subsequently facilitates the recruitment and activation of the type I receptor (Massagué, 2000, Lin et al., 2006). The fact that TGF $\beta$ are found in dimers allow the recruitment of two type II receptors and two type I receptors, where type II receptors phosphorylate the type I receptors at the $\mathrm{N}$ terminal serine-threonine site (Mueller \& Nickel, 2012, Macias et al., 2015).

Binding of the TGF $\beta$ superfamily members to their specific receptor complexes results in the phosphorylation of intracellular secondary messengers SMADs \{which is homologous to the Drosophila protein, mothers against decapentaplegic (MAD) and the Caenrhabditis elegans protein small (SMA)\} through the activation of the serine-threonine kinases (Kawabata et al., 1998, Macias et al., 2015). There are a total of eight SMAD protein isoforms (SMAD 18), and different ligand groups phosphorylate different SMAD complexes. For example, TGF $\beta$ and activin activates SMAD 2 and 3, whereas the BMPs activate SMAD 1, 5, and 8 (Kawabata et al., 1998). These SMADs, known as receptorregulated (R-) SMAD's, have a Ser-X-Ser motif at the C-terminal, which will be phosphorylated by type I receptors (Macias et al., 2015). The SMAD 4 protein is known as the common (co-) SMAD and following SMAD phosphorylation, is able to form homo- and hetero-trimers with the R-SMADs. This then recruits specific transcriptional co-regulators to the SMAD transcriptional complex that later translocates to the nucleus and regulate transcription (Kawabata et al., 1998, Juengel \& McNatty, 2005, Macias et al., 2015). The SMADs 6 and 7 are inhibitory (i) SMADs that prevent the cellular signal (Kawabata et al., 1998, Juengel \& 
McNatty, 2005). A study using E.coli identified that SMADs exist as monomers prior to the activation of the TGF $\beta$ receptors (Kawabata et al., 1998). As the receptors are activated, the SMADs start to form complexes; homo- and heterooligomers, which afterwards either bind to DNA binding proteins, or directly bind to DNA (Kawabata et al., 1998). It has been found that interferon- $\gamma$ inhibits SMAD signaling by up-regulating inhibitory SMAD7 mRNA levels thereby inhibiting the TGF $\beta$ receptors ability to phosphorylate the targeted SMAD's (Ulloa et al., 1999). This suggests a cross talk between the SMAD pathway and several intracellular signaling pathways (Ulloa et al., 1999, Yu, 2002, Shimasaki et al., 2004).

\subsection{Growth Differentiation Factor 9 and Bone Morphogenetic Protein 15}

\subsubsection{Overview}

It was thought that the oocyte played a passive role in the development and progression of the follicle, specifically with its neighbouring somatic cells (Gilchrist et al., 2008). However, the oocyte has now been shown to play a central role in regulating follicular growth and ovulation rate through oocytesecreted factors, such as GDF9 and BMP15 (Gilchrist et al., 2008). GDF9 and BMP15 are members of the TGF $\beta$ superfamily that are exclusively localised within the ovarian follicle. GDF9 and BMP15 are expressed within, and secreted from, the oocyte in most mammalian species (Shimasaki et al., 2004, Juengel \& McNatty, 2005). Labelling the oocyte using specific mono-and poly-clonal antibodies against GDF9 and ovine BMP15 appeared to show the localisation of the antigens in the oocyte at different follicular stages (Juengel et al., 2002). The oocyte labelling was abolished when an antisera for GDF9 and BMP15 were preincubated with GDF9 immunising peptide and ovine BMP15 mature protein, confirming the specificity of the label and that GDF9 and BMP15 are exclusively secreted from oocyte (Juengel et al., 2002). 
The expression of the Gdf9 gene is initiated prior to the assembly of the follicles, whereas the Bmp15 gene is found to start expressing at the primordial follicle stage in mice and rats, and at the primary follicle stage (Type 2 follicle) in sheep (Shimasaki et al., 2004; McNatty et al., 2007). The relative level of expression of Gdf9 and Bmp15 mRNA differs among different mammalian species, thus differing ratios of Gdf9: Bmp15 mRNA have been shown to correlate with ovulation rate in some poly-ovulatory (e.g. mice and rats, which ovulate more than ten oocytes per cycle), and typically mono-ovulatory (e.g. sheep, red deer and cow, which usually ovulate only one oocyte per cycle) species (Crawford and McNatty, 2012). The Gdf9: Bmp15 mRNA ratios for mice and rats were high (5.91, 3.65) due to a higher relative mRNA expression of Gdf9 than Bmp15.

Furthermore, the ratio tends to decrease with decreased ovulation rate, which was found to be lowest in the red deer and cow ( 0.10 and 0.24 , respectively) (Crawford and McNatty, 2012). However, the polyovulatory pig was an exception to the aforementioned pattern, where the level of GDF9: BMP15 mRNA ratio was low ( 0.5) (Crawford and McNatty, 2012). Nevertheless, the ratio of Gdf9:Bmp15 mRNA is reported as being species specific (Crawford and McNatty, 2012).

As mentioned above, GDF9 and BMP15 play a major role in the development, growth, and health of ovarian follicles. Indeed, GDF9 is essential for follicular growth to proceed past the primordial follicle stage and onto the primary follicle stage, the formation of corpora lutea, and organisation of the granulosa cell layers (Dong et al., 1996). BMP15 was found to support the follicular transition from primary to secondary stage and select the dominant healthy follicles that will be ovulated (Shimasaki et al., 2004). Moreover, both growth factors regulate the proliferation of granulosa cells, the development of thecal cells, and suppress apoptosis of cumulus cells (Dong et al., 1996, Shimasaki et al., 2004). The mean diameter of the oocyte, estrus cycle behavior, corpora lutea number, and ovulation rate are all found to be regulated by GDF9 and BMP15 (Juengel et al., 2002). For example, a smaller oocyte diameter was observed following the immunisation against either GDF9 or BMP15 peptides (Juengel et al., 2002). It has been noted that treating cumulus cell-oocyte complexes (COC) with 
recombinant forms of GDF9 and BMP15 increased the health and number of COCs that developed following fertilisation to reach the blastocyst stage (Hussein et al., 2006, Yeo, et al., 2007).

\subsubsection{Mutations and Immunization Studies}

The critical role of the GDF9 and BMP15 in follicular growth and development has been further confirmed using animals that either have naturally-occurring mutations in the coding regions of the GDF9 and BMP15 genes or where the GDF9 and/or BMP15 gene has been removed ('knocked-out'; KO). The homozygous-KO mice studies have revealed that while Bmp15\% and Gdf9\% KO males, and the $B m p 15 \%$ females were fertile, the $G d f 9 \%$ females were infertile (Dong et al., 1996). Moreover, follicular development in these Gdf9\% mice did not go beyond the primary follicle stage, which are follicles comprised of one layer of granulosa cells (Dong et al., 1996). The ovaries of these Gdf9\%- mice were smaller than wild-type ovaries, lacked corpora lutea, and growing follicles displayed an asymmetric organization of atypical granulosa cells (Dong et al., 1996). The effect of a homozygous knockout of Bmp15 on female mice did result in a reduced ovulation rate and fertility rate but they displayed relatively typical follicular growth (Yan et al., 2001). A fascinating study illustrated that doublemutated mice carrying $\mathrm{Gdf} \mathrm{9}^{+/-}$and $\mathrm{Bmp} 15 \%$ mutations expressed severe fertility defects compared to the mice with Bmp15\% alone (Yan et al., 2001, Su et al., 2004).

Also, several natural mutations have been observed in the GDF9 and BMP15 genes in sheep (Juengel et al., 2002, Hanrahan et al., 2004). Sheep GDF9 has been mapped using a probe that targeted a 277 bp genomic DNA fragment of ovine GDF9, which located the gene on chromosome 5 between BM7247 and SRCRSP14 markers (Sadighi et al. 2002). Sheep with homozygous mutations in the GDF9 gene (e.g. Cambridge, and Belclare) showed similar results to the Gdf9\% KO mice whereby these ewes were completely sterile. Conversely, heterozygous GDF9-/+ mutations in sheep tend to increase the ovulation rate (Hanrahan et al., 2004, Juengel \& McNatty, 2005). 
However unlike in the mouse, the homozygous mutation in BMP15 also significantly affected follicular growth resulting in follicular arrest at the primary follicle stage (Galloway et al., 2000, Hanrahan et al., 2004). Generations of Rasa Aragonesa sheep generated from three sires that exhibited a high estimated breeding value were investigated to illustrate if major gene mutations was the reason for their high fecundity phenotype (Martinez-Royo et al., 2008). The analysis showed that the daughters of these sires represented a high estimated breeding value, while the daughters of the sons from these sires exhibited a low estimated breeding value, suggesting that a heterozygous mutation present on the $\mathrm{X}$ chromosome is associated with fertility and litter size in these sheep (Martinez-Royo et al., 2008). Thereafter, a 17 bp deletion mutation was identified on the BMP15 locus, which is located on the $\mathrm{X}$ chromosome, resulting in a high breeding value in heterozygous ewes (Martinez-Royo et al., 2008).

Finally it has been noted that carrying a heterozygous mutation on both the GDF9 and BMP15 genes would greatly increase ovulation rate in ewes (Hanrahan et al., 2004). The inactivating mutations that have been observed in the GDF9 and BMP15 genes in sheep have all shared a similar phenotype in that homozygousity causes infertility and heterozygousity increases the ovulation rate. Moreover, a dosage effect has been observed for both proteins (Juengel \& McNatty, 2005, Otsuka et al, 2011).

Another approach using strong immunisations against either a GDF9 peptide, BMP15 peptide, or BMP15 mature protein in sheep elicits similar results to that in ewes with natural homozygous mutations in GDF9 or BMP15 whereby follicular growth arrests at the transitory or primary stage. Furthermore, passive and partial immunisation to GDF9 or BMP15 in sheep elicited a similar result to that observed in heterozygous $G D F 9^{-/+}$or $B M P 15^{-/+}$-mutated sheep whereby a significant increase in fertility and ovulation rate was observed (Juengel et al., 2002, Juengel \& McNatty, 2005). 
Given that an active immunisation against the proregions of GDF9 and BMP15 increased the number of corpora lutea and decreased the number of offspring in mice (McIntosh et al., 2012), it has been suggested that the proregion of GDF9 and BMP15 may play a key role in regulating ovarian function.

\subsubsection{Structural Characteristics}

As members of the TGF $\beta$ superfamily, GDF9 and BMP15 share similar structural characteristics. They are both synthesised as preproproteins including a large proregion and a smaller, biologically-active mature region that are separated by a conserved basic amino acid sequence RXXR (Juengel \& McNatty, 2005). Moreover, western blotting studies illustrate that GDF9 and BMP15 can be found in several molecular forms; promature and mature forms (monomers) as well as, homodimers and multidimers (Edwards et al., 2008). An immunoblot of recombinant GDF9 based on mouse cDNA identified two bands of mature GDF9 with an apparent molecular size of 15 and $19 \mathrm{kD}$. Another band at 60-80 kD was presumed to be the uncleaved premature form of GDF9 (Hayashi et al., 1999, Hsueh et al., 2000). A comparison of the rat GDF9 amino acid sequence against the mouse and human sequence reveals that the overall homology with the rat and human are $91 \%$ and $74 \%$, respectively, whereas the homology in the mature part is $96 \%$ and $92 \%$, respectively (Hayashi et al., 1999). Also, it has been determined that GDF9 has three conserved glycosylation sites in the proregion and a single putative $\mathrm{N}$-linked glycosylation site in the mature region (Hayashi et al., 1999). Recombinant mouse GDF9 is suggested to be produced in a glycosylated form as the $19 \mathrm{kDa}$ band decreased to a $15 \mathrm{kDa}$ band following treatment with $\mathrm{N}$-glycosidase F (Hayashi et al., 1999, Hsueh et al., 2000). The alignment of the amino acid sequences of rat, pig, sheep and red deer reveal that the rat has the least homology when compared against sequences in the pig (71\%), sheep (69\%), and red deer (71.5\%), whereas sheep and red deer sequences are found to be highly homologous (95\%) (Figure 1.1).

A unique feature of GDF9 and BMP15 is the replacement of the fourth conserved cysteine by serine. This fourth conserved cysteine is responsible for the 
formation of the intermolecular disulfide bond between the monomers, (Laitinen et al., 1998). However, the absence of the intermolecular disulfide bond between the monomers in the mature region of GDF9 and BMP15 suggests their associations in solution, as either homo- or hetero- dimers, must be via noncovalent bonds (Juengel \& McNatty, 2005, Edwards et al., 2008, Mottershead et al., 2013).

Also, the synthesis of cumulin and pro-cumulin, which are heterodimers of mature and promature GDF9:BMP15, respectively and its ability to increase the tritiated-thymidine incorporation in granulosa cells as well as improve oocyte quality supports the possible formation of heterodimers (Mottershead et al., 2015). The heterodimers of GDF9 and BMP15 were produced through the reintroduction of the conserved cysteine, instead of the serine (Mottershead et al., 2015). Therefore to date, there is no published evidence that heterodimers of native BMP15 and GDF9 form in biological fluids (Edwards et al., 2008).

Similar to TGF $\beta$, the proregion of GDF9 and BMP15 is known to assist the folding, dimerisation, secretion, stability and non-covalent interactions with the mature part (McIntosh et al., 2011). Even after cleavage, the proregion remains associated with the mature region and may even associate with the mature region of the other protein. For example, a co-immunoprecipitation study revealed that the BMP15 proregion associated with the mature GDF9 protein and vice versa which suggest the formation of hetero-multimeric complex are also possible (McIntosh et al., 2008, McIntosh et al., 2011).

\subsubsection{Receptors and Signaling}

The binding of the GDF9 ligand through the recruitment and formation of the BMPRII and ALK5 receptor complex activates the SMAD 2 and 3 signaling molecules (Juengel \& McNatty, 2005). However, BMP15 activates the SMAD 1,5, and 8 signaling molecules, through the receptor complex of BMPRII and ALK6 (Juengel \& McNatty, 2005). A study on the proliferation of rat granulosa cells measured by tritiated-thymidine incorporation investigated the essential 
Key

N-terminal

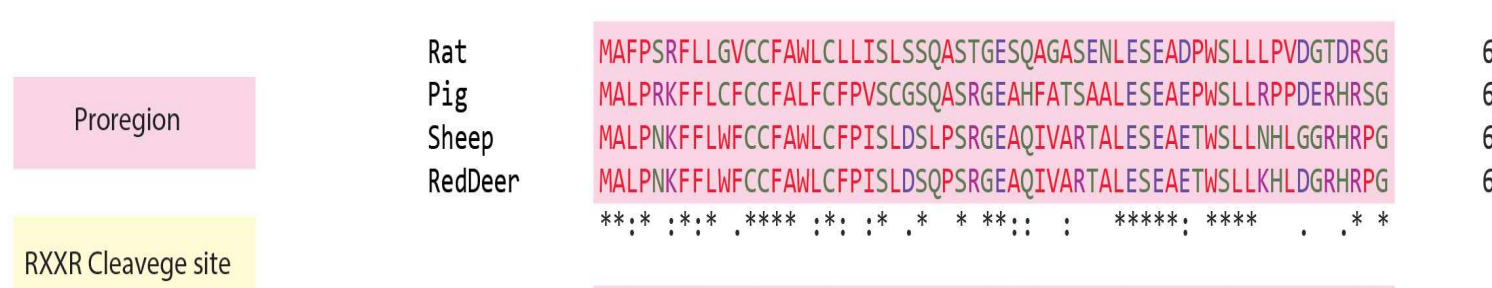

Mature region

Rat
Pig
Sheep
RedDeer

LLPPLFKVLSDRRSETPKLQPDSRALYYMKKLYKTYATKEGVPKPSRSHLYNTVRLFSPC

Residue Properties

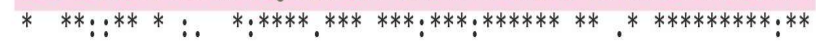

Red - Small, hydrophobic, Aromatic

Rat

AQQEQAPSNQMTGPLPMVDLLFNLDRVTAMEHLLKSVLLYTLNNSAASSSTVTCVCDLW

Pig

AQHKQAPGDQVTGTLPSGDLRFNLDRVTAVEHLLKSVLLYTWNNSISFPSPVKCECSLW

Blue - Acidic

RedDeer

AQQKQAPGDQ-AGTLPSVDLLFNLDRVTVVEHLFKSVLLYTFNNSISFPFPVKCVCNLVI

$* *::^{* * *} .::^{*}:^{*} \quad * * * * * * * * * .: *^{* *}: * * * * * * * * * *: \quad * * * . * *$ :

Purble - Basic (except H)

Rat

Green - Hydroxyl + Sulfhydryl + amine $+G$

KEPMSSSKATPRAPYSFTL------RKHRWIEMDVTSLLQPLVASSERSIHLSVNFTCT

Pig KEPELSNKTLPKAPYSFTLNSPFTFQKKHHKIEIDVTAILQPLWSNKREIHMSIDFTCV

Sheep KEPEFSSKTLPRAPYSFTYNSQFEFRKKYKWMEIDVTAPLEPLVASHKRNIHMSVNFTCA

\section{Consensus Symbols}

* - Single fully conserved residue

Rat

Pig

RDQAP - - - ENGTFNMPLSVPPSLILYLNDTSTQAYHSWQSLQQSTQRHSQHPGQD-SVTT

: - Strongly similar properties $>0.5$ in Gonnet PAM 250 matrix

- - Weakly similar properties $=<0.5$ in Gonnet PAM 250 matrix

Rat

Pig

KDQLOHRSAQDSLFNMTLLVAPSLLLYLNDTSAQAFHRWHSLHPKKRPSQGPDQKRGLSA

\section{Percent Similarity}

Sheep

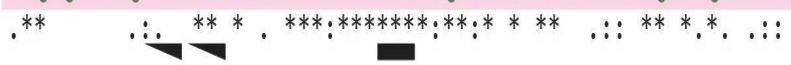

RPVEEEATEVERSPRHRRGQKTLSSETKKPL-TASFNLSEYFRQFLFPQNECELHDFRLS

$\begin{array}{lllll}\text { Rat } & 100.00 & 71.00 & 68.86 & 71.53\end{array}$

$\begin{array}{lllll}\text { Pig } & 71.00 & 100.00 & 81.31 & 84.42\end{array}$

Sheep $\begin{array}{llll}68.86 & 81.31 & 100.00 & 94.69\end{array}$

$\begin{array}{llll}\text { Red Deer } 71.53 \quad 84.42 \quad 94.69 & 100.00\end{array}$

\section{Rat}

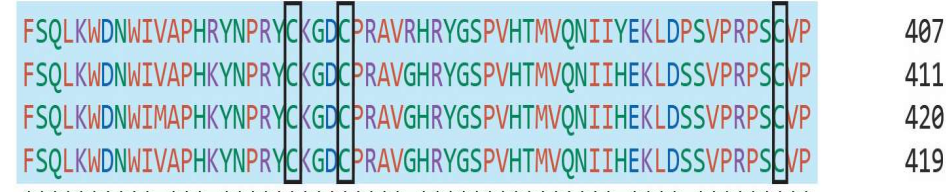

RedDeer

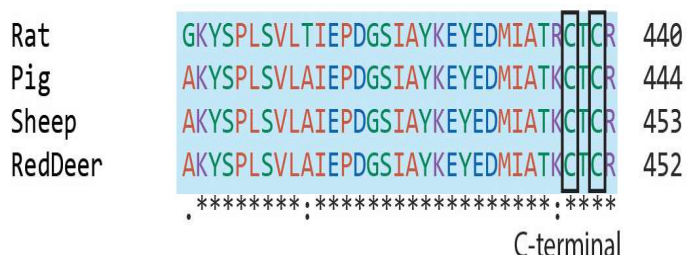

Figure 1.1: Alignment of the amino acid sequences of GDF9 in different mammalian species. The amino acid sequences were obtained from the National Cental for Biotechnology Information. The accession codes for the rat, pig and sheep sequences are NP_067704.1, AAT67460.1, and CCI87994.1 respectively. The red deer sequenc was kindly donated by J. Juengel (AgResearch Invermay, NZ). The shading represent different structures of the protein. The borders represent the six conserved cysteine residues. The letters for each protein residue are coloured according to their properties. The black box under the sequences represent putative N-linked glycosylation site among all species, whereas half filled box represent possible species difference in glycosylation site. 
receptors that initiate the signal (Edwards et al., 2008). Using human recombinant IgG targeting specific TGF $\beta$ receptors indicated that blocking the BMPRII by the recombinant IgG reduced the level of incorporation significantly, whereas blocking other type II and type I did not have a significant effect (Edwards et al., 2008). The fact that only blockage of BMPRII affected proliferation rate, suggests that the ligands (GDF9 or BMP15) bind firstly to BMPRII, which in turn recruit a type I receptor to mediate the signal (Edwards et al., 2008). Moreover, blocking either ALK5 or ALK6 did not affect the proliferation rate of the granulosa cells, though the existence of both ligands GDF9 and BMP15 at the same time suggests that they may act as heterodimers as a result of an earlier interaction (Edwards et al., 2008).

Furthermore, the synergistic action of GDF9 and BMP15 has been reported to occur through the SMAD 2/3 pathway in the sheep and mouse (Reader et al., 2012). This study reported a total or partial block in proliferation rate of granulosa cells co-cultured with either rat or sheep GDF9+BMP15 and inhibitors of the SMAD 2/3, but not the SMAD 1/5/8 pathway (Reader et al., 2012). Other signaling pathways also play a role in stimulating granulosa cells to proliferate under the action of GDF9 and BMP15. In the sheep, inhibitors of the nuclear factor-қßB completely blocked the stimulatory action of GDF9+BMP15 on granulosa cell proliferation rate. In the rat and the sheep, inhibitors of the p38mitogen-activated protein kinase (MAPK) pathway partially reduced granulosa cell proliferation rate after treatment with either murine or ovine recombinant GDF9 and BMP15 treatment (Reader et al., 2012). In contrast, c-Jun N-terminal kinase inhibitors increased the stimulatory action of GDF9+BMP15 on granulosa cell proliferation rate in the rat. These finding could suggest that the differences observed between species in regards to the synergistic actions of GDF9 and BMP15 could be facilitated through the utilization of divergent non-SMAD signaling pathways (Reader et al., 2012).

Another in vitro study used purified recombinant GDF9 and BMP15 mature region alone to investigate the signaling pathways associated with their observed synergistic effects at low doses (<20 ng)(Mottershead et al., 2012). As 
expected, both GDF9 and BMP15 mature region increased the proliferation rate of granulosa cells, and adding them together increased the proliferation rate over and above that of an additive effect (Mottershead et al., 2012). Using CAGAluciferase, the combined action of GDF9 and BMP15 activated the SMAD3 signaling pathway, whilst no significant activation of the SMAD1/5/8 pathway was observed (Mottershead et al., 2012). On the other hand, using several inhibitors for different signaling pathways, the synergistic effect was decreased in a dose-dependent manner when the SMAD2/3, MAPK, or Rous Sarcoma oncogene signaling pathways were inhibited, whereas the addition of inhibitors for the nuclear factor kappa B pathway did not affect granulosa cell proliferation rate (Mottershead et al., 2012). These findings suggest the activation of other non-SMAD signaling pathways contribute to granulosa cell proliferation under the action of GDF9 and BMP15, but it is still ambiguous how and when these pathways are activated (Reader et al., 2012, Mottershead et al., 2012). The signaling pathway utilised by a heterodimer of GDF9 and BMP15 could be inferred from the pathways activated via synthetic cumulin and pro-cumulin (Mottershead et al., 2015). It is suggested that the inherent asymmetry of the heterodimer, a complex with two BMPRII receptors, one ALK4/5/7, and ALK6 is formed which leads to the activation of both the SMAD2/3 and SMAD1/5/8 pathways (Mottershead et al., 2015). In comparison to GDF9, which showed activation of SMAD2/3 pathway, and BMP15, which showed activation of SMAD1/5/8 signaling pathway, pro-cumulin activated the SMAD 3 and SMAD 1/5/8 pathways (Mottershead et al., 2015).

\subsubsection{Synergistic Effects}

A study of the synergistic effects of GDF9 and BMP15 on cultured murine granulosa cells (Mottershead et al., 2012) indicated that treating granulosa cells with both ligands simultaneously, significantly improved the proliferation rate over and above that of a calculated additive effect. The incorporation of the tritiated-thymidine in granulosa cells was about 40 times more than control cells and eight times more than after the addition of GDF9 or BMP15 alone (Mottershead et al., 2012). The synergistic effect of GDF9 and BMP15 was also 
observed at the level of SMAD activation within the cell (Mottershead et al., 2012). These facts suggest that both GDF9 and BMP15 are essential for their actions on regulating follicular growth, granulosa cell proliferation and ovulation rate (Otsuka et al, 2011).

A synthetic recombinant of a heterodimer of GDF9 and BMP15 termed cumulin was produced where it exhibited an activation of both signaling pathways that are associated with GDF9 and BMP15 (Mottershead et al., 2015). The heterodimer was produced in two different versions: a heterodimer made of two proproteins of GDF9 and BMP15 termed pro-cumulin and; a heterodimer comprised of two mature proteins of GDF9 and BMP15 known as cumulin (Mottershead et al., 2015). Cumulin exhibited a greater effect on tritiatedthymidine incorporation into granulosa cells than when incubated with recombinant forms of GDF9 and BMP15 either individually or collectively (Mottershead et al., 2015). Interestingly, treatment of porcine oocytes with procumulin led to improved oocyte quality in regards to morphological expansion of cumulus cells, the number of blastocysts that cleaved, and the number of blastocysts that hatched (Mottershead et al., 2015). 


\subsection{Significance of the Study}

It is now recognised that the oocyte secreted growth factors GDF9 and BMP15 play a significant role in determining ovulation rate and litter size. As such, differences in these growth factors between species may also, at least in part, be responsible for the differences observed in litter sizes between mammalian species. In support of this hypothesis, the ratios of Gdf9:Bmp15 mRNA expression levels differ between, and are unique to each, mammalian species. Moreover, Gdf9:Bmp15 mRNA expression levels have been reported to be higher in polyovulatory species (e.g. rat) and lower in mono-ovulatory species (e.g. red deer) (Crawford and McNatty, 2012). An exception to this pattern has been noted in the pig where this polyovulatory species has a low GDF9:BMP15 mRNA ratio (Crawford and McNatty, 2012). Whilst previous studies focused on using recombinant GDF9 to determine the molecular structure, it is wise to compare and measure the native forms that are found within and secreted from the oocyte of different species to represent a clearer idea of the biologically-relevant molecular forms of GDF9. The species considered in the following study were selected to represent a range of non-rodent species that differ in ovulation rate, and to compare these with a polyovulatory rodent species. Thus oocytes from the rat, sheep, pig, and red deer were used in this study and represent litter sizes of 7-16, 1-3, 14-22, and 1, respectively. The molecular forms of GDF9 will be identified and the amounts of protein synthesised and secreted from the oocyte will be estimated.

Understanding the differences in the molecular forms of GDF9 across different species that exhibit a range of litter size may aid in understanding fertility disorders and developing new therapeutic approaches, as well as improve the efficiency of current artificial reproductive technologies such as in vitro maturation (IVM) and in vitro fertilisation (IVF). 


\subsection{Aims}

The overall aim of this study was to

Determine the molecular forms of native GDF9 that are expressed within (intra-oocyte) and secreted from (oocyte conditioned media) the oocyte in four mammalian species that differ in litter size.

To address this aim, western blots were performed using oocyte lysates and oocyte conditioned media of rat, sheep, pig, and red deer.

The specific aims are:

1. Determine the relative amounts of each molecular form of GDF9 relative to each other both within and across the different species.

To address this aim, densitometry analysis was performed on the bands observed following western blotting that corresponded to different molecular forms of GDF9.

2. Determine the efficiency of a novel monoclonal antibody targeting GDF9 (MAB37G) across the species.

To address this aim, western blots were performed on oocyte lysates of different mammalian species comparing the new monoclonal (MAB37G) GDF9 antibody with a previously characterised monoclonal antibody (MAB37A).

3. Determine the biological activity of pig recombinant GDF9 and BMP15 and the ability of a new (MAB37G), compared to a previouslycharacterised (MAB37A), monoclonal antibody in recognising the biologically-active forms of the recombinant proteins used.

To address this aim, sheep granulosa cells were incubated with recombinant pig GDF9 and BMP15, in the absence or presence of either 
monoclonal GDF9 or BMP15 antibody. Tritiated- thymidine incorporation was measured to assess the proliferation rate of granulosa cells. 


\section{Materials \& Methods}

The recipes for the solutions used in this study are listed in Appendix I. The companies from which all the chemicals used in this study were purchased are listed in Appendix II.

\subsection{Western Blot}

\subsubsection{Sample collection for western blots}

Pre-pubertal female Sprague-Dawley rats aged between 3-4 weeks were provided by the School of Psychology at Victoria University of Wellington. Rats were euthanised by asphyxiation using $\mathrm{CO}_{2}$ gas, and ovaries were extracted and transported back to the laboratory in extraction media (M199 containing PenStrip and HEPES; Appendix I). Cumulus cell-oocyte complexes (COCs) were isolated from the ovaries using a $20 \mathrm{G}$ needle to tear the follicular wall and release the COC into the extraction media. Once a sufficient number of COCs had been collected, they were transferred into a $1.5 \mathrm{~mL}$ eppendorf tube $(100$ COCs/tube) using a micropipette.

Sheep ovaries from lambs and ewes of unknown background were provided by Taylor Preston meat processing plant in Ngauranga, Wellington, NZ. The ovaries were transported back to the laboratory on ice. Upon arrival, ovaries were immediately washed with $0.9 \%$ sterile saline (Appendix I), briefly ( $\sim 10$ seconds) immersed in $70 \%$ ethanol (Appendix I) to remove any possible bacterial contamination, and rinsed again in $0.9 \%$ sterile saline. Ovaries were then trimmed of extraneous tissues and stored in $0.9 \%$ saline until COC extraction. To extract COCs, each ovary was transferred into extraction media, and dissected through the hilum along the midline. Using a dissection microscope (Model MZ95, Leica) and a 20G needle, the follicular wall in each visible antral follicle was torn to release the COC into the extraction media. Once a sufficient number of COCs had been collected, they were transferred into a $1.5 \mathrm{~mL}$ eppendorf tube (100 COCs/tube) using a micropipette. 
Ovaries from red deer of unknown backgrounds were provided by the Venison Packers Feilding Ltd, Feilding, Manawatu, NZ. The ovaries were transported back to the laboratory in a vacuum flask containing $0.9 \%$ sterile saline within three hours of collection. Upon arrival, ovaries were processed and COCs were extracted in a similar manner to that for the sheep samples.

Pig ovaries from sows of unknown background were provided by Cabernet Foods, Kintyre Meats Ltd in Gladstone, Wairarapa, NZ. The ovaries were transported back into the laboratory in a vacuum flask containing $0.9 \%$ sterile saline within two hours of collection. Upon arrival, the ovaries were washed in manner similar to that for the sheep and red deer ovaries. The COCs were extracted by puncturing all visible follicles with a $20 \mathrm{G}$ needle. Due to the abundance of the follicles and the large amount of cellular debris in the extraction media, the extraction media containing the COCs was run through $70 \mu \mathrm{M}$ strainer. Using fresh extraction media, the surface of the strainer was washed to collect the COCs. A point of difference between the COCs from the pig, and those from the other species used in this study was that the majority of oocytes collected from the pig were denuded. In contrast, the majority of oocytes collected from the other species (i.e. rats, sheep and red deer) were surrounded by multiple layers of cumulus cells (i.e. COCs). Once a sufficient number of denuded oocytes and COCs had been collected, they were transferred into a $1.5 \mathrm{~mL}$ eppendorf tube (100 COCs/tube) using a micropipette.

For the obtainment of oocyte lysate samples from all species, Eppendorf tubes containing 50, or $100 \mathrm{COCs}$ were immediately centrifuged at $500 \mathrm{~g}$ for 4 minutes. The media was discarded and $1 \mu \mathrm{L}$ of $10 \mathrm{x}$ protease inhibitors (Appendix I) was added to the COC pellet and the samples were stored at $-80^{\circ} \mathrm{C}$ for future use.

For the obtainment of conditioned media samples (media containing the native secretions from COCs) from all species, aliquots of 100 COCs were collected into eppendorf tubes and centrifuged at $500 \mathrm{~g}$ for 4 minutes. The media was discarded and $25 \mu \mathrm{L}$ of incubation media (Appendix I) was added. The tubes containing $100 \mathrm{COCs}$ each were incubated in a $37^{\circ} \mathrm{C}$ incubator (for rat samples) or $39^{\circ} \mathrm{C}$ incubator (for sheep, pig, and red deer samples) $\left(5 \% \mathrm{CO}_{2}, 95 \%\right.$ humidity) for 18 hours. Following the incubation period, the tubes were 
centrifuged at $500 \mathrm{~g}$ for 4 minutes and the supernatant was transferred, without disturbing the COC pellet, into a new eppendorf tube. Finally, $2.5 \mu \mathrm{L}$ of $10 \mathrm{x}$ protease inhibitors (Appendix I) was added to the media supernatent and stored at $-80^{\circ} \mathrm{C}$ until further processing.

\subsubsection{Positive and negative control samples}

In-house media containing HEK 293 recombinant pig GDF9 (secreted media), which was used as positive control, and media containing HEK 293 recombinant pig BMP15 (secreted media) was used as negative control. These controls were made in-house by the Reproduction Biology group at Victoria University of Wellington.

\subsubsection{SDS PAGE formation}

The preparation of an SDS gel involved a small and a large glass plate with a built-in spacer being assembled on the gel holder. The separating gel (Appendix I) was poured between the plates ensuring a $1 \mathrm{~cm}$ space at the top. A small layer of distilled water $\left(\mathrm{dH}_{2} \mathrm{O}\right)$ was then applied and the gel was left for 1 hour to allow for polymerisation to occur. The $\mathrm{dH}_{2} \mathrm{O}$ layer was then removed, and the stacking gel (Appendix $I$ ) was poured into the remaining gap. A 10 -well comb was inserted into the stacking gel to form the wells and the gel was left for a further 30 minutes to polymerize.

\subsubsection{Sample preparation}

The sample aliquots were defrosted and briefly vortexed. The oocyte lysates samples were then diluted in $20 \mu \mathrm{L}$ of M199 media to give an estimated final volume of $25 \mu \mathrm{L}$. The samples containing $25 \mu \mathrm{L}$ of conditioned media was used undiluted. To obtain a divergent pool of sample, aliquots of either oocyte lysates or conditioned media were mixed together to create one pool of sample of either oocyte lysates or conditioned media, respectively. Thereafter the pooled sample was divided into two portions to be subjected to either non-reducing (addition of $25 \mu \mathrm{L}$ of $2 \mathrm{x}$ non-reducing buffer (Appendix 1)) or reducing (addition of $25 \mu \mathrm{L}$ of 2x sample buffer (Appendix I) conditions. To prepare the controls, $2 \mu \mathrm{L}$ of either 
positive or negative control media was added to $23 \mu \mathrm{L}$ of M199 media. A

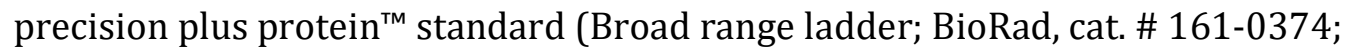
USA, CA) was used to indicate band size. An aliquot $(2 \mu \mathrm{L})$ of the ladder was diluted in $23 \mu \mathrm{L}$ of M199 media. Later, 1:1 ratio of 2x sample buffer was added to each well aliquoted tube. For crosslinking studies, bissulfosuccinimidyl suberate (Appendix II) was added at a final concentration of $2 \mathrm{mM}$ for 30 minutes, then $2 \mathrm{x}$ reducing sample buffer was added at a 1:1 ratio. The samples and the ladder were then denatured for 5 minutes at $95-100^{\circ} \mathrm{C}$. The denatured samples were immediately loaded into the gel to be electrophoresed.

\subsubsection{Gel electrophoresis}

After comb removal, the gels were assembled in a Bio-Rad running cassette and placed into a mini-protean tetra cell (BioRad; USA, CA). Approximately $500 \mathrm{~mL}$ of $1 \mathrm{x}$ running buffer (Appendix I) was poured over the cassette until the bottom electrode in the mini-protean tetra cell was covered. As the sample volume was larger than the well capacity, samples were carefully added into the wells and electrophoresed for a few minutes to allow the sample to enter the gel before refilling the well with the remainder of the sample. The gels were electrophoresed at $150 \mathrm{~V}$ until the blue dye front reached the bottom of the gel (approximately 1 hour and 15 minutes).

\subsubsection{Gel transfer}

The separated protein bands were transferred from the gel to GE Hybond C+ membrane by assembling the transfer cassette in the following order; red side of cassette, Scotch-Brite ${ }^{\circledR}$ pad, 2x blotting paper, membrane, gel, 2x blotting paper, Scotch-Brite ${ }^{\circledR}$ pad, black side of cassette. The cassette layer was placed in the Mini-protean II cell tank (BioRad; USA, CA) and filled with transfer buffer (Appendix I). The protein transfer was performed at $100 \mathrm{~V}$ for 1 hour at $4^{\circ} \mathrm{C}$. Later, the cassette layers were dismantled and the visible ladder bands were marked by pencil on the blot. The membrane was then placed in a square petri dish and subjected to 2 x 10 minute washes in membrane washing buffer (Appendix I). 


\subsubsection{Membrane blocking}

The non-specific binding of the antibodies was blocked by incubating the membrane in $5 \%$ blocking buffer (Appendix I) for 1 hour at room temperature.

\subsubsection{The primary antibody incubating conditions}

Different concentrations of the blocking buffer (Appendix $I$ ) and primary monoclonal antibody (MAB) were tested to determine the optimal (lowest) concentrations that effectively blocked non-specific, but allowed sufficient specific, binding of the primary monoclonal antibody (MAB). The primary antibody incubation buffer for the MAB37A and MAB61A (Appendix III) antibodies consisted of a final antibody concentration of $1 \mu \mathrm{g} / \mathrm{mL}$ in $5 \%$ blocking buffer. The primary antibody incubation buffer for the MAB37G (Appendix III) antibodies consisted of a final antibody concentration of $2 \mu \mathrm{g} / \mathrm{mL}$ in $0.5 \%$ blocking buffer. Thus, following the blocking step described above (Section 2.1.7), the membranes were incubated overnight on a rocking plate at room temperature in the primary antibody incubation buffer.

The specificity of the antibody was tested to differentiate between the bands that were positive for GDF9, and the bands that were positive (false positive) for another component of the MAB. An aliquot of $8.8 \mu \mathrm{L}$ of the primary antibody (MAB37A) was pre-incubated with $40 \mu \mathrm{L}$ of lysate from E.coli transfected with the ovine GDF9 gene and $700 \mu \mathrm{L}$ of $5 \%$ blocking buffer in a 1.5 eppendorf tube. The pre-incubation reaction was carried out on a shaker for 3 hours. Later the pre-incubation reaction mix was added to the $5 \%$ blocking buffer. The membranes were then incubated overnight at room temperature on a rocking plate.

\subsubsection{Secondary antibody incubation}

The membrane was washed 3x 10 minutes with the membrane-washing buffer (Appendix I). A final concentration of 1:3000 of anti-mouse IgG-HRP conjugate antibodies (Appendix III) was diluted in $5 \%$ blocking buffer (Appendix I) and was 
used as the secondary antibody incubation buffer. The membrane was incubated in the secondary antibody incubation buffer for two hours at room temperature on a rocking plate.

\subsubsection{Developing the membrane}

The membrane was washed 3x 10 minutes in membrane-washing buffer (Appendix I) and then sprayed with luminal: $\mathrm{H}_{2} \mathrm{O}_{2}$ spray (Western Bright ${ }^{\mathrm{TM}}$ ECLSpray; Advantsa, K-12049-D50). The spray was applied carefully to the membrane surface and incubated for 5 minutes. After the incubation period, the membrane was dried and placed directly in the Omega Lum G documentation system (Aplegen; USA, CA) to capture the results.

\subsubsection{Determining exposure length}

The membranes were subjected to an exposure period of 10 seconds, 1 minute, or 10 minutes and the pictures were saved as raw Tiff files for further analyses.

\subsubsection{Stripping the membrane}

Membranes were stripped of bound antibodies for the purpose of either comparing the antibody affinity differences, checking for band specificity by reprobing with a pre-absorbed MAB, or identifying both GDF9 and BMP15 on the same blot. To strip the membrane, $100 \mathrm{~mL}$ of stripping buffer (Appendix I) was added to a $200 \mathrm{~mL}$ sealable Klip It ${ }^{\mathrm{TM}}$ container (Sistema) and preheated in a $50^{\circ}$ -

$60^{\circ} \mathrm{C}$ water bath for 30 minutes. Later, membranes were added to the pre-heated stripping buffer ensuring the entire surface was submerged. The membranes were incubated for 30 minutes within the $50^{\circ}-60^{\circ} \mathrm{C}$ water bath and were given a gentle shake every 5 minutes. Thereafter, membranes were washed 3x 10 minutes in washing buffer (Appendix I). A one-hour blocking incubation step with $5 \%$ blocking buffer was applied before commencing with further primary and secondary incubations. 


\subsubsection{Calculating band size}

To estimate the molecular sizes of the bands, $\mathrm{R}_{\mathrm{f}}$ values (where $\mathrm{R}_{\mathrm{f}}=$ the distance migrated by the protein / the distance migrated by the dye front for the resolving portion of each gel) were calculated. The values on the ladder were used as a reference. The $\mathrm{R}_{\mathrm{f}}$ values of the ladder were plotted on the $\mathrm{x}$-axis against the $\log _{10}$ of the corresponding molecular size to create a linear regression line. Later, using the linear regression equation of the best fit line, the molecular size value of each band were calculated from the $R_{f}$ values of the chemiluminescent identified bands. The band size was estimated in this manner across all replicate blots.

\subsubsection{Densitometric analysis}

Densitometry analysis of the relative band densities were performed by Image J software (version 1.50i with Java 1.8.0_77 64-bit; National Institutes of Health $(\mathrm{NIH})$ ). The Tiff files representing blots under reducing conditions were captured by Omega Lum G documentation system (Aplegen; USA, CA) and transferred to a PC to be analysed. The Tiff files were filtered first for levels of saturation, which was determined by Image Studio Lite Version 5.2 (Li-COR Biosciences). Those band were deemed not to be saturated were chosen. Then, the filtered files were selected based on a common exposure length across all files.

The densitometry analysis was performed independently for each replicate to account for the inter blot variations. The file of the replicate was transferred into Image J software to measure the mean grey value of the bands that correspond to promature and mature forms using a unified rectangular selection size across all replicates. To standardise the data, the background of the file was measured and subtracted from the band readings. Additionally, the readings were adjusted by the number of oocytes divided by 100 . Finally, the data was normalised by correcting against the measurement of the positive control band (recombinant pig GDF9 mature protein). Thus, adjusted and normalised densitometry data of the promature and mature bands from the three replicate experiments were estimated for each species. 


\subsection{Methyl- ${ }^{3} \mathrm{H}$-thymidine uptake bioassay}

\subsubsection{Sample collection}

Sheep ovaries were processed as described above (Section 2.1.1). Following the extraction of COCs from ovarian follicles, all visible denuded oocytes and COCs were transferred to a fresh petri dish and the remaining media that contained granulosa cells (GCs) were transferred to a $15 \mathrm{~mL}$ falcon tube. The GC sample was centrifuged at $150 \mathrm{~g}$ for 5 minutes. Afterwards, the media was carefully removed avoiding pellet disruption and $1 \mathrm{~mL}$ of cell culture medium (Appendix $I$ ) was added to wash the cells. The sample was again centrifuged and the media removed. A final volume of $1 \mathrm{~mL}$ of cell culture medium was added to the cell pellet and incubated in a $37^{\circ} \mathrm{C}$ water bath to maintain the cell viability until further use.

\subsubsection{Cell counting}

An aliquot of $50 \mu \mathrm{L}$ of the cell sample was added to $5 \mu \mathrm{L}$ of Trypan blue and loaded onto a haemocytometer. The numbers of viable (clear) and non-viable (blue) cells that were characteristic of granulosa cells (large granular-like cells with a visible nucleus) were counted to estimate the number of granulosa cells in the $1 \mathrm{~mL}$ sample. The total granulosa cell number was calculated using the following formula and a master cell solution with a concentration of 1000 cells/ $\mu \mathrm{L}$ was prepared.

$\mathrm{N}=\mathrm{X} * 25 / \mathrm{Y}^{*} 10^{4 *} \mathrm{~V}$

Where:

$\mathrm{N}=$ total cell number

$\mathrm{X}=$ number of cells counted under the haemocytometer

$\mathrm{Y}=$ number of squares counted on the haemocytometer

$\mathrm{V}=$ total volume of cell suspension (in this case $1 \mathrm{~mL}$ ) 


\subsubsection{Testing the ability of the GDF9 and BMP15 monoclonal antibodies to recognise biologically-active forms of GDF9 and BMP15}

To study the biological effect of recombinant pig GDF9 and BMP15, proliferation bioassay were performed whereby recombinant pig GDF9 and BMP15 were added to cultured sheep granulosa cells. Thereafter, the ability of the various MABs used in this study were tested for their ability to identify the biologicallyactive forms of their target molecules. These experiments were performed by incubating the recombinant proteins with their corresponding MABs, and testing their proliferative effect on cultured sheep granulosa cells.

Using a 96-well plate, $20 \mu \mathrm{L}$ of the master cell solution (Section 2.2.2) containing 20000 viable cells was added to each well. An aliquot of $1 \mu \mathrm{L}$ of media containing HEK 293 recombinant pig GDF9 and/or BMP15 was added and a final volume of $55 \mu \mathrm{L}$ was reached with cell culture medium. For the MAB neutralisation tests, two approaches were undertaken. Firstly co-incubation was tested whereby pig recombinant proteins were added to the sheep granulosa cells together with 10 $\mu \mathrm{M}$ of their target antibodies (Appendix III) for the full incubation period: Secondly, pre-incubation was tested whereby the pig recombinant proteins were pre-incubated with $10 \mu \mathrm{M}$ of their target antibody (Appendix III) in the cell culture medium for 2 hours prior to their addition to sheep granulosa cells. Prior to their addition to the culture system, the pre-incubation solution was centrifuged at $11300 \mathrm{~g}$, and $35 \mu \mathrm{L}$ of the top surface supernatant were carefully aliquoted into the assay wells. The antibodies used to target GDF9 were MAB37A and MAB37G, whereas the antibodies used to target BMP15 were MAB61A and MAB61B.

Each assay contained a positive and negative control. The positive control consisted of sheep granulosa cells cultured with either GDF9 or BMP15. The negative control consisted of sheep granulosa cells alone. Each treatment was tested in three well replicate for one assay, where the full assay was repeated three times. The wells on the edge of the plate were filled with $55 \mu$ l of cell culture medium to reduce media dehydration in the test wells. Then, plates were placed in $39^{\circ} \mathrm{C}$ incubator ( $5 \% \mathrm{CO}_{2}, 95 \%$ humidity) for 16 hours. Thereafter, 
methyl- ${ }^{3} \mathrm{H}$-thymidine was diluted $25 \mathrm{x}$ times with cell culture medium (Appendix I) to add $10 \mu \mathrm{l}$ of the diluted stock $(\sim 10 \mu \mathrm{Ci}$; SciMed, NZ) to each well and placed in the incubator for another 6 hours.

\subsubsection{Harvesting and methyl- ${ }^{3} \mathrm{H}$-thymidine uptake measurement}

By the end of the incubation period, the cells were harvested using a cell harvester (TOMTEC, mod. No. MACH 3-FM series). A 90 x $120 \mathrm{~mm}$ glass fibre mat (Perkin Elmer, printed Filtemat A, Cat. No. 1450-421) was placed in the cell harvester to collect the cells on the plates, where the glass fibre mat was dried and heat sealed in a plastic sleeve (Perkin Elmer sample bag, Cat. No. 1450-432) with $4.5 \mathrm{~mL}$ of scintillation fluid (Beta Scint, Perkin Elmer, Cat. No. SC/9200.21). Finally, the sealed glass fibre mat was placed in a beta counter (Perkin Elmer, 1450-SLC MicroBetaTriLux) to measure radioactivity as count per minute per well, accumulated over a 2 min interval. The data obtained were adjusted by subtracting the average reading obtained from the wells that contained only media alone.

\subsection{Statistical analysis}

\subsubsection{Densitometry analysis}

The adjusted and normalised data of the three replicates of each species were entered into GraphPad prism software (version 6.01; GraphPad), where a twoway ANOVA was performed followed by a Bonferroni's post-hoc test were used when significance differences were identified within and between species in regards to the amount of promature and mature forms of GDF9 that were detected.

\subsubsection{Methyl- ${ }^{3} \mathrm{H}$-thymidine uptake}

The adjusted counts of the three wells of one assay replicate were averaged. To test for the proliferation induced by the recombinant proteins, fold change was calculated by dividing on the average count obtained from the negative control, which was the average count of incubating granulosa cells alone. To test for the 
MAB ability to recognise the biological-active form, fold change was calculated by dividing on the average count of the positive control, which the average count of the granulosa cells and its corresponding recombinant. Each assay was replicated three times, and each assay was treated independently. Using GraphPad Prism software (version 6.01; GraphPad) a one-way ANOVA was performed and if significant differences were identified, a Bonferroni's post-hoc test was performed. 


\section{Chapter 3: Results}

\subsection{Estimation of the concentration of recombinant pig mature GDF9 conditioned media produced by HEK-293 cells}

To estimate the amount of recombinant pig mature GDF9 protein produced by HEK293 cells, it was compared to a previously-characterised E.coli-produced ovine GDF9 protein of known concentration. The samples were processed under reducing conditions and MAB37A were used to detect the bands denoting GDF9. A dilution series of the recombinant ovine GDF9 was used as a standard curve and processed alongside that of the HEK293-expressed pig GDF9 protein. Using densitometry, an estimate of the amount of protein in the conditioned media produced by pig GDF9-transfected HEK293 cells were determined (Figure 3.1 A). The band size of ovine GDF9 mature protein was detected at $\approx 19 \mathrm{kDa}$, whereas the mature band of pig GDF9 was detected at $\approx 18 \mathrm{kDa}$ (Figure $3.1 \mathrm{~A}$ ). The band densities for each serial dilution were plotted and fitted using linear regression (Figure $3.1 \mathrm{~B}$ ). The coefficient of determination $\left(\mathrm{R}^{2}\right)$ for serial dilutions of Eccoliand HEK293-expressed GDF9 were 0.942 and 0.955 , respectively. The density of $16 \mathrm{ng}$ of the E.coli produced ovine GDF9 was excluded as it had reached saturation levels. Using the standard curve of the E.coli-produced GDF9, the concentration of HEK293-produced pig GDF9 was $0.94 \mathrm{ng} / \mu \mathrm{L}$ (95\% CI range is $0.84,1.09)$. 
A

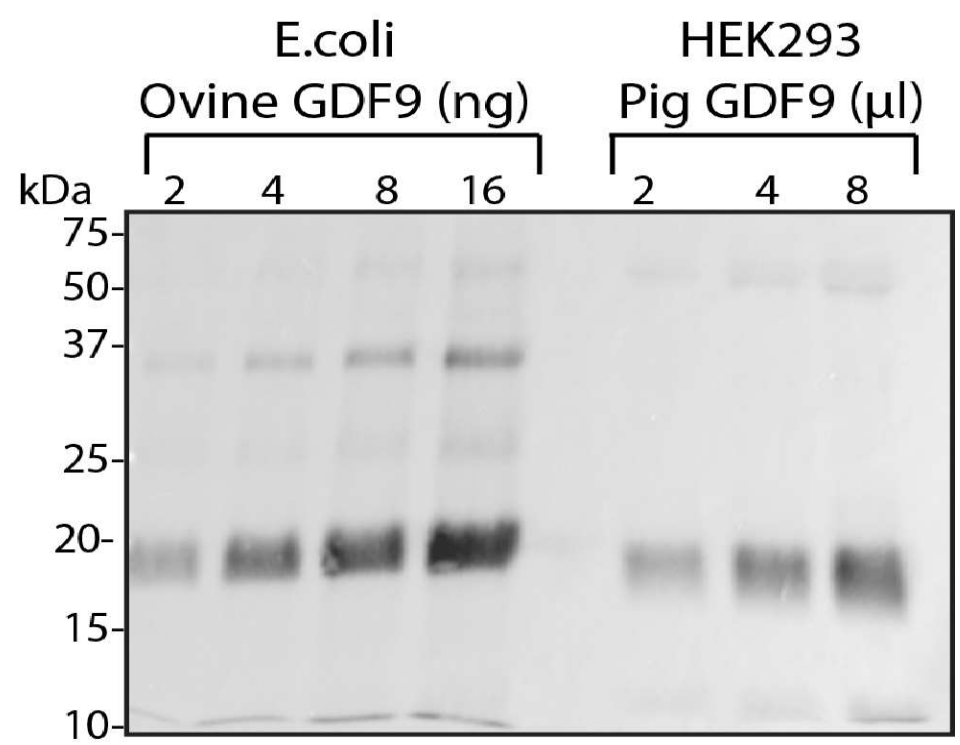

B
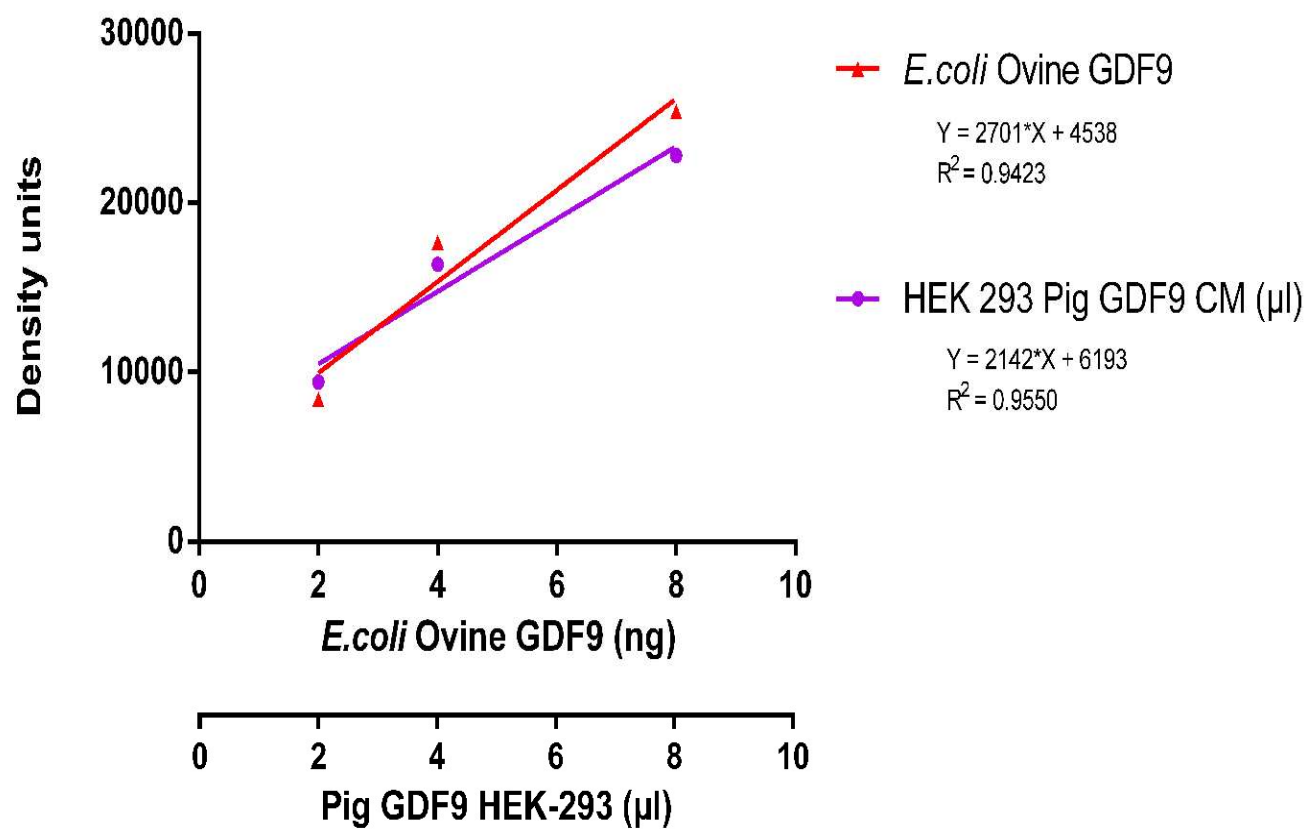

Figure 3.1: Estimation of the pig mature GDF9 produced by HEK 293. (A) Western blotting of the titration of ovine GDF9 produced in E.coli; lanes 1-4, and the titration of the conditioned media of the recombinant HEK 293 producing pig GDF9; lanes 6-8. (B) Scatter blot of the densities of the mature GDF9 found; red data set represent ovine GDF9 produced in E.coli which relate to the top $x$-axis, and purple data set represent pig GDF9 produced by recombinant HEK 293 which relate to the bottom $x$-axis. . 


\subsection{The molecular forms of GDF9 found within and secreted from the oocyte of mammalian species}

\subsubsection{Rats (litter size 7-16)}

In order to identify the molecular forms of GDF9 that were present within and secreted from rat oocytes, a series of western blots were performed. For each replicate, pools of 150 rat oocytes were used either directly after collection (oocyte lysate) or following an 18 hour incubation period (conditioned media). The oocyte lysate and conditioned media samples were subjected to nonreducing and reducing conditions, as well as to crosslinking agents to investigate possible dimerisation under reducing conditions. The molecular forms of GDF9 were recognised by MAB37A. The average molecular sizes of the bands were calculated based on the three replicates collected for each condition (i.e. reducing, non-reducing, cross-linked under reducing).

Across all replicates, GDF9 was barely detectable in oocyte lysates under nonreducing conditions. After an extended exposure time was applied, a faint band GDF9 promature band was noted at $\approx 55 \mathrm{kDa}$ (Figure $3.2 \mathrm{~A}$ ). Under reducing conditions however, visible bands of both promature and mature forms of GDF9 were detected at $\approx 55 \mathrm{kDa}$ and $\approx 26 \mathrm{kDa}$, respectively, in oocyte lysate after a long exposure time. No secreted forms of GDF9 were detected in media under non-reducing or reducing conditions. The crosslinking treatment resulted in the appearance of a high molecular size band across all the samples, which might be the result of an interaction of GDF9 with other proteins.

The specific size of the over-saturated positive control (recombinant pig GDF9) was hard to identify due to the long exposure time applied to visualise the faint bands of GDF9. Interestingly, the crosslinking treatment induced the formation of a band of molecular size $\approx 37 \mathrm{kDa}$, which suggests the possibility of a dimer form in pig recombinant GDF9. The band observed in negative control appeared only once out of more than 25 blots (Figure 3.2 B). 

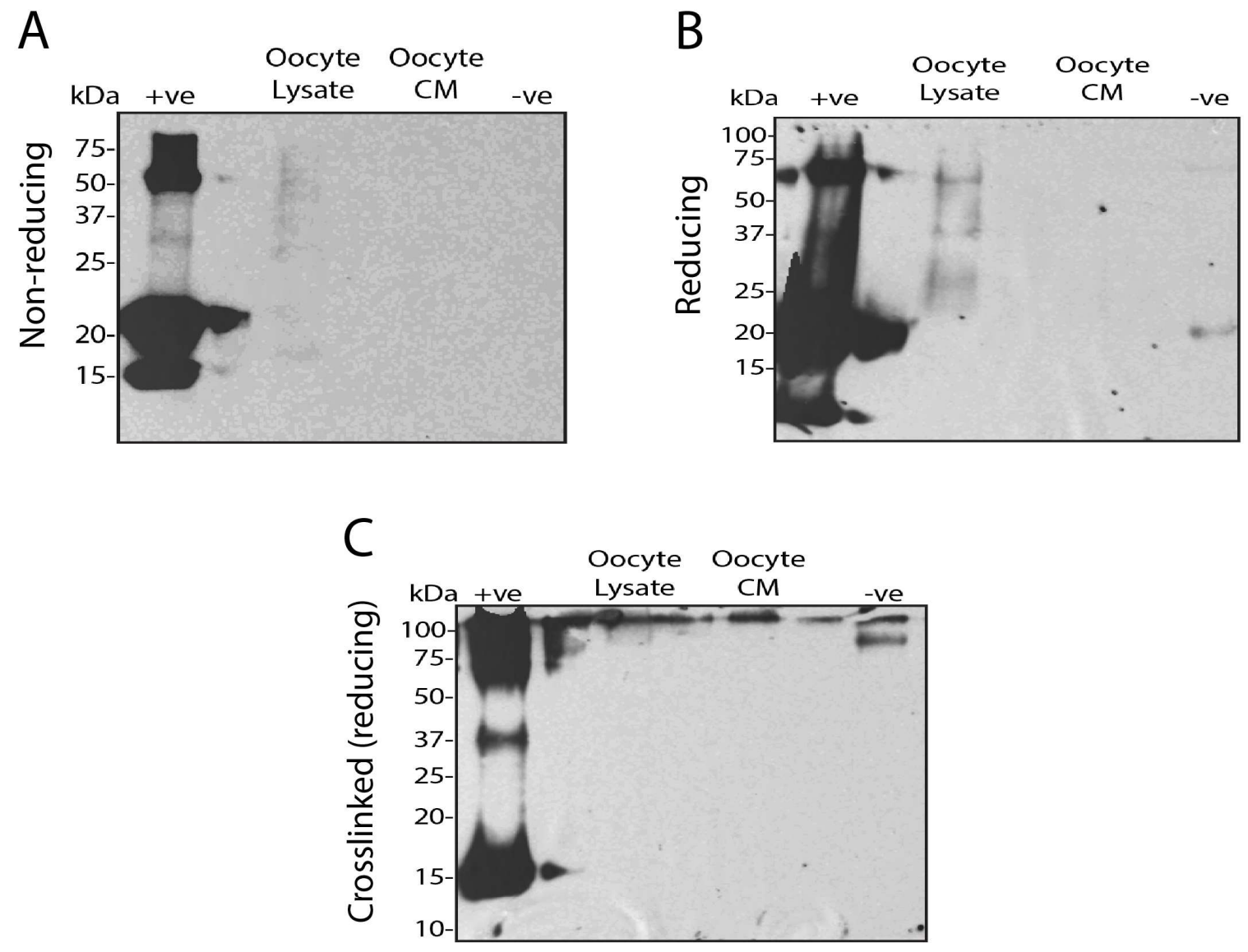

Figure 3.2: GDF9 molecular forms found within and secreted from rat oocyte. Western blots were prepared under non-reducing $(A)$, reducing (B), and crosslinking agent prior reducing (C) treatments. Each blot has in lane 1: HEK 293 producing pig GDF9 as positive control, lane 3: oocyte lysates, lane 5: oocyte conditioned media, lane 7: HEK 293 producing pig BMP15 as negative control.

\subsubsection{Pigs (litter size 14-22)}

To determine the molecular forms of GDF9 within and secreted from pig oocytes, pools of 100 pig oocytes were collected immediately as oocyte lysates or were incubated for 18 hours (conditioned media). The average molecular sizes of the bands were calculated based on three replicates of each treatment.

Across all treatments (non-reducing, reducing, and crosslinking with reducing), GDF9 was visible as several molecular forms. Under non-reducing conditions, 
promature and mature forms of GDF9 were detected in oocyte lysates at $\approx 62$ $\mathrm{kDa}$ and $\approx 15 \mathrm{kDa}$, respectively. The conditioned media also revealed faint bands of secreted promature and mature GDF9 forms (Figure $3.3 \mathrm{~A}$ ). Interestingly, a band at a high molecular size was observed in all oocyte lysate replicates under non-reducing conditions suggesting multimers of GDF9 (Figure $3.3 \mathrm{~A}$ ). Bands corresponding to promature and mature forms of GDF9 $(\approx 58 \mathrm{kDa}$ and $\approx 12 \mathrm{kDa}$, respectively) were present in both oocyte lysates and oocyte conditioned media under reducing conditions (Figure 3.3 B). It was noted that the bands intensity increased under reducing conditions, coincident with the disappearance of the high molecular size band (Figure 3.3 B). Applying the crosslinking agent to both oocyte lysates and oocyte conditioned media revealed a high molecular size band suggesting the formation of multimers, as well as faint bands that correspond to the promature form of GDF9 in the oocyte lysates only (Figure $3.3 \mathrm{C}$ ).

The recombinant pig GDF9 revealed bands at similar molecular sizes as that detected in oocyte lysates and conditioned media (Figure 3.3 A\&B). Applying the crosslinking agent on the recombinant pig GDF9 resulted in the detection of a faint band that could be a mature dimer, with no corresponding band found in either oocyte lysate or oocyte conditioned media.

To test the specificity of MAB37A, the antibody was preabsorbed with lysates of E.coli-produced ovine GDF9 prior to incubating with the pig samples under reducing conditions (Figure 3.3 D). The bands that were identified under reducing conditions (c.f. Figure 3.3 B) were no longer identifiable, suggesting no cross reactivity of the antibody to similar proteins and provides support of antibody specificity. 
A

Oocyte Oocyte Oocyte

kDa tve Lysate CM -ve CM(OE)

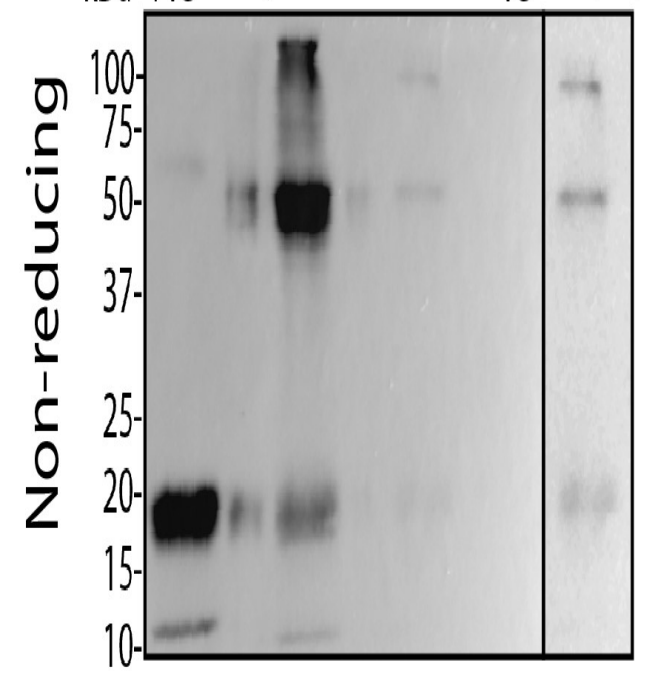

Oocyte Oocyte Oocyte

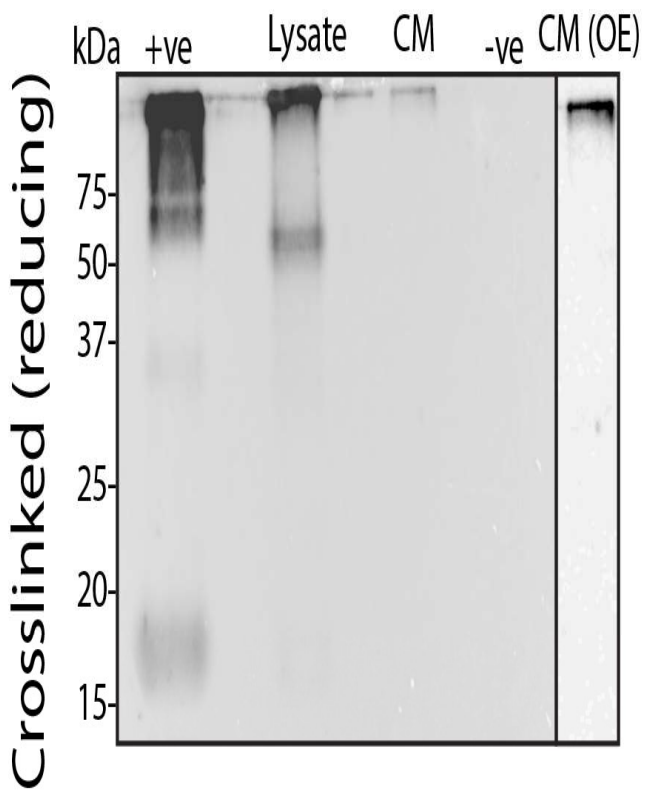

$B$

Oocyte Oocyte Docyte
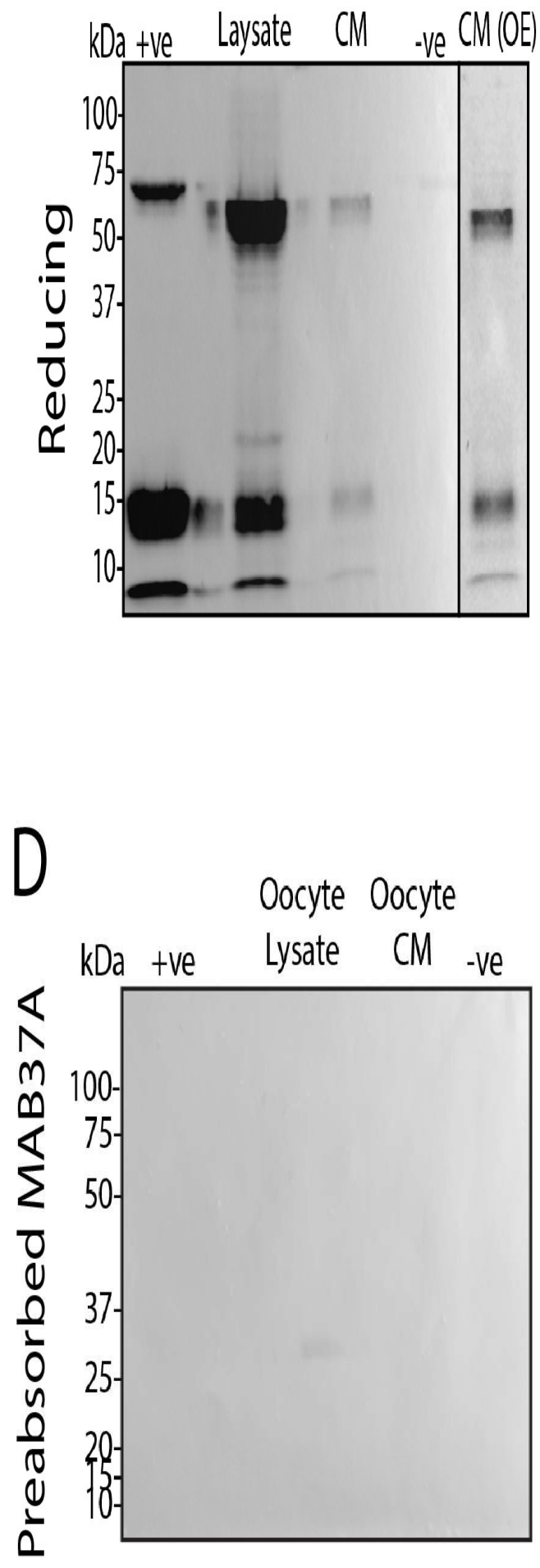

Figure 3.3: GDF9 molecular forms found within and secreted from pig oocyte. Western blots were prepared under non-reducing $(A)$, reducing (B), and crosslinking agent prior reducing (C) treatments. (D) is a stripped blot then reprobed with MAB37A preabsorbed with E.coli lysates producing ovine GDF9. Each blot has in lane 1: HEK 293 producing pig GDF9 as positive control, lane 3: oocyte lysates, lane 5: occyte conditioned media, lane 7: HEK 293 producing pig BMP15 as negative control. 


\subsubsection{Sheep (litter size 1-3)}

To determine the molecular forms of GDF9 within and secreted from sheep oocytes, pools of 100 sheep oocytes were either collected immediately as oocyte lysates or were incubated for 18 hours (conditioned media). The average molecular sizes of the bands were calculated based on three replicates of each treatment.

Under all conditions (non-reducing, reducing, and crosslinked with reducing), promature and mature forms of GDF9 was observed in oocyte lysates at molecular sizes of $\approx 60 \mathrm{kDa}$ and $\approx 16 \mathrm{kDa}$, respectively (Figure 3.4). Faint bands representing secreted promature and mature forms of GDF9 were observed in secreted media under extended exposure times (Figure 3.4 A). Subjecting the samples to reducing conditions resulted in a slight reduction in the size of the mature band $(\approx 14 \mathrm{kDa}$ ) (Figure $3.4 \mathrm{~B}$ ).

Applying the crosslinking agent to the samples showed similar molecular forms (promature and mature) to non-crosslinked samples, however a high molecular size band was also evident. This band could correspond to multimer forms in both the oocyte lysates and the conditioned media, which was, also, identified in the rat and pig samples (Figure 3.4 C).

The pre-absorption results of incubating the antibody with lysates of E.coli used to produce GDF9 (Figure 3.4 D) and then with sheep samples again revealed that MAB37A appears to be specific for GDF9 proteins. 
$A$

Oocyte Oocyte Oocyte

KDa +ve Lysate CM -ve CM (OE)

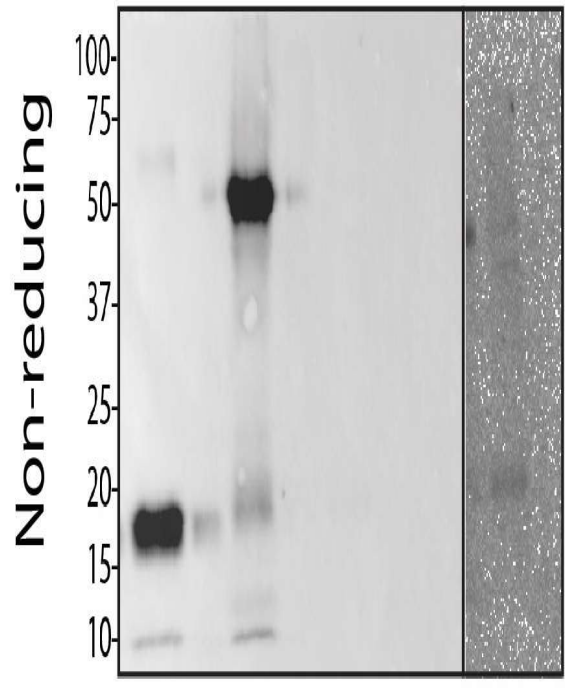

B

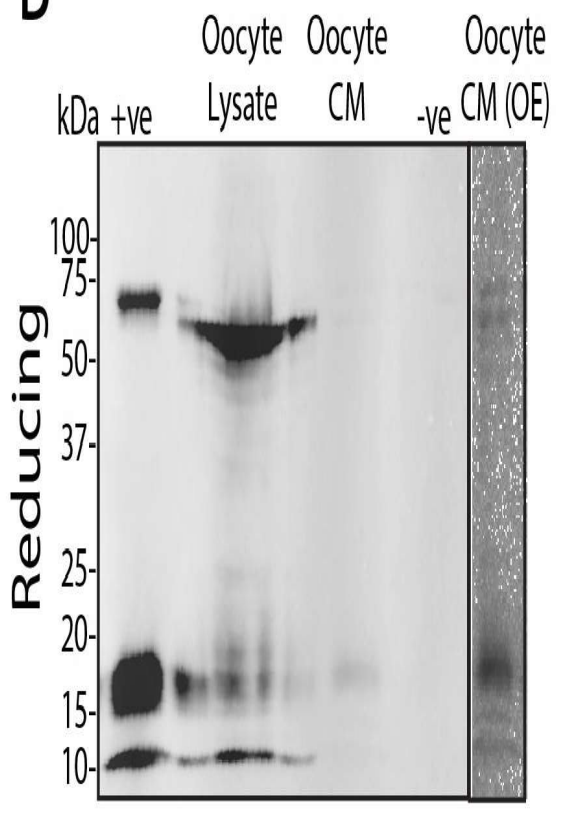

C

Oocyte Oocyte Oocyte

D

Oocyte Oocyte
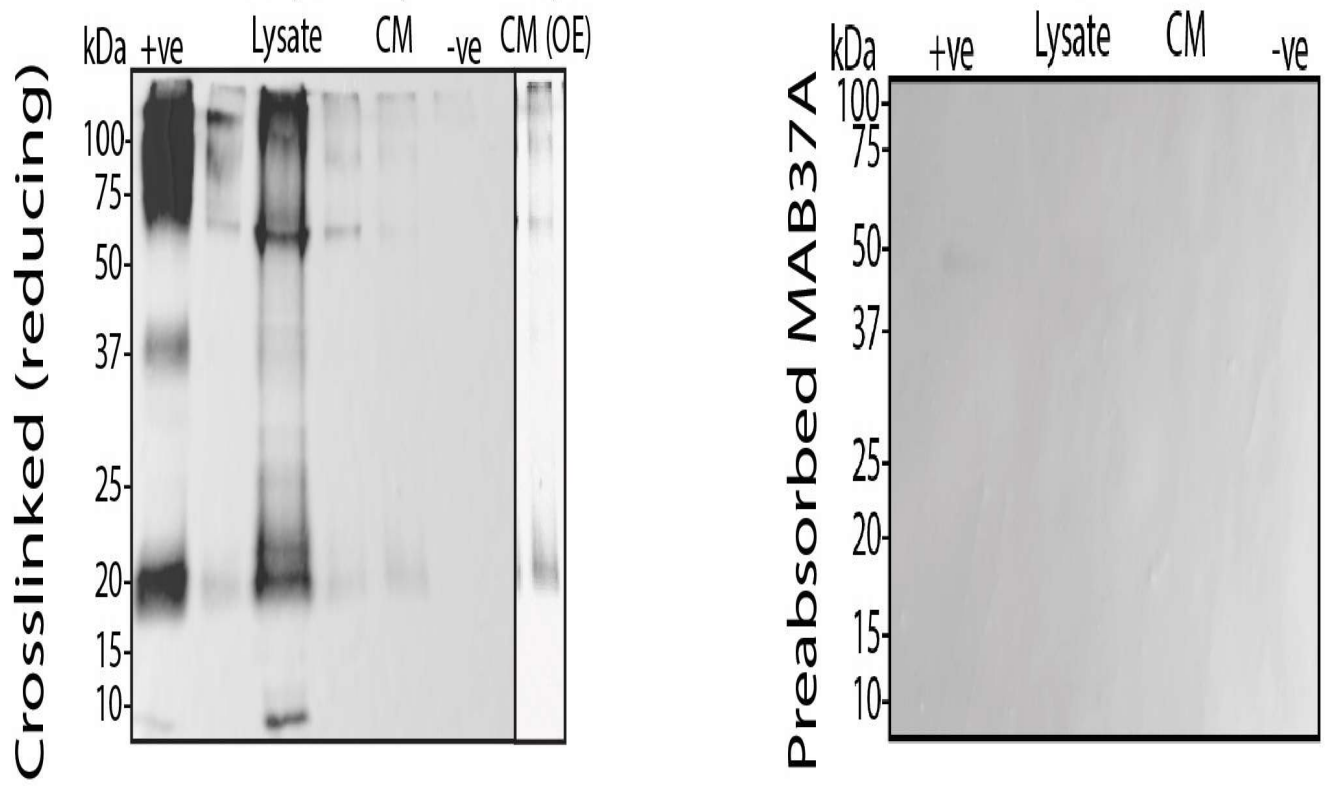

Figure 3:A: GDF9 molecular form found within and secreted from sheep oocyte. Westem blots were prepared under non-reducing (A) reducing (B), and crosslinking agent prior reducing (C) treatments. (D) is a stripped blot then reprobed with MAB37A preabsorbed with E.coli lysates producing ovine GDF9. Each blot has in lane 1: HEK 293 producing pig GDF9 as positive control, lane 3: occytelysates, ane 5: 0ocyte conditioned media, lane 7: HEK 293 producing pig BMP15 as negative control. 


\subsubsection{Red deer}

To determine the molecular forms of GDF9 within and secreted from red deer oocytes, pools of 100 red deer oocytes were either collected immediately as oocyte lysates or incubated for 18 hours (conditioned media). The molecular sizes of the bands were estimated based on the average of three replicates of each treatment.

As observed in all other species tested in this study (rat, pig and sheep), promature and mature forms of GDF9 were detected under non-reducing and reducing conditions. Under non-reducing conditions, both the oocyte lysates and secreted media samples revealed bands representing promature $(\approx 67 \mathrm{kDa})$ and mature $(\approx 16 \mathrm{kDa})$ GDF9. Under reducing conditions, bands representing both promature and mature GDF9 were detected strongly in oocyte lysates and faintly in conditioned media. Again, subjecting the samples to reducing conditions resulted in a slight reduction in the molecular size of both the promature $(\approx 63$ $\mathrm{kDa})$ and mature $(\approx 14 \mathrm{kDa})$ bands.

Applying the crosslinking reagent to the red deer samples showed similar results to that observed for pig and sheep oocyte lysates and sheep conditioned media (Figure $3.3 \mathrm{C}, 3.4 \mathrm{C}$ ). Promature and mature forms of GDF9 were observed in both oocyte lysates and conditioned media (Figure 3.5 C). A consistent high molecular size band was also observed in the red deer samples, similar to that observed in all other species tested.

The pre-absorption results of incubating the antibody with lysates of $E$.coli used to produce GDF9 and then with red deer samples again revealed that MAB37A appears to be specific for GDF9 proteins (Figure 3.5 D). 

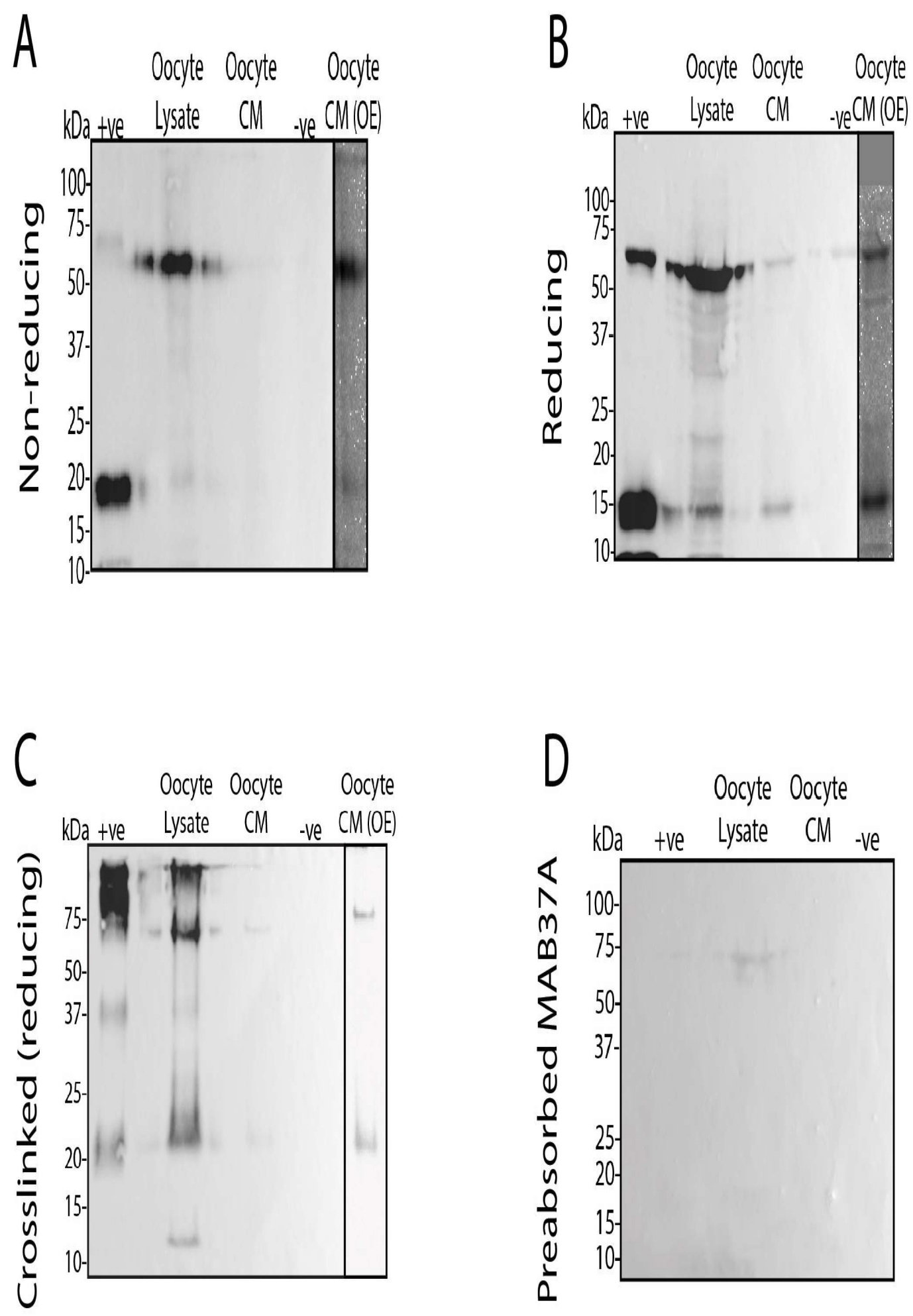

Figure 3.5: GDF9 molecular forms found within and secreted from deer oocyte. Western blots were prepared under non-reducin! $(A)$, reducing $(B)$, and crosslinking agent prior reducing (C) treatments. (D) is a stripped blot then reprobed with MAB37A preabsorbed with E.coli lysates producing ovine GDF9. Each blot has in lane 1: HEK 293 producing pig GDF9 as positive control, lane 3 oocyte lysates, lane 5: 0ocyte conditioned media, lane 7: HEK 293 producing pig BMP15 as negative control. 


\subsection{Species comparisons of molecular forms of GDF9}

The previous section explored the molecular forms of GDF9 that are produced within and secreted from oocytes of four different species that differ markedly in litter size. Comparisons of the molecular size s of each form of GDF9 in all the species tested are illustrated in Table 1 and Figure 3.6. The forms that were common amongst all species were the promature and mature forms. The molecular size s of the mature form of GDF 9 were similar in the pig, sheep and red deer (15-16 $\mathrm{kDa})$ but higher in the rat $(26 \mathrm{kDa})$. The molecular size of the promature form of GDF9 under non-reducing conditions varied slightly between species (rat $\sim 55 \mathrm{kDa}$, pig $\sim 62 \mathrm{kDa}$, sheep $\sim 60 \mathrm{kDa}$ and red deer $\sim 67 \mathrm{kDa}$; Figures $3.6 \mathrm{~A} \& D$ ). Unexpectedly, GDF9 was not detected in the secretions of rat oocytes under any of the conditions (Figure 3.6 D).

As noted earlier in section 3.2, non-reducing conditions tended to cause an increase in the molecular sizes of the GDF9 proteins compared to those under reducing conditions (Figures $3.6 \mathrm{~B} \& \mathrm{D}$ )

Results from the pig indicated that under non-reducing conditions, the forms of GDF9 present in the oocyte lysate and in secreted media include a high molecular size multimer, as well as both the promature and mature forms. This presumptive multimer form was absent in all other species. Overall, applying a crosslinking agent appeared to cause a decrease in the intensity of the promature and mature forms of GDF9, concomitant with the appearance of a multimers band (Figure 3.6 C\&F). 
Table 1: A summary of the observed and the molecular sizes of the forms of GDF9 under different conditions identified across the studied species.

\begin{tabular}{|c|c|c|c|c|c|}
\hline $\begin{array}{l}\text { Molecular } \\
\text { form }\end{array}$ & $\begin{array}{c}\text { PAGE } \\
\text { condition }\end{array}$ & Rat & Pig & Sheep & Red Deer \\
\hline \multirow{3}{*}{ Promature } & $\begin{array}{l}\text { Non- } \\
\text { reducing }\end{array}$ & $\approx 55 \mathrm{kDa}$ & $\approx 62 \mathrm{kDa}$ & $\approx 60 \mathrm{kDa}$ & $\approx 67 \mathrm{kDa}$ \\
\hline & Reducing & $\approx 55 \mathrm{kDa}$ & $\approx 58 \mathrm{kDa}$ & $\approx 60 \mathrm{kDa}$ & $\approx 63 \mathrm{kDa}$ \\
\hline & $\begin{array}{c}\text { Crosslinked } \\
\text { (observed) }\end{array}$ & $x$ & $\begin{array}{c}\checkmark \\
\text { (Oocyte } \\
\text { lysate only) }\end{array}$ & $\checkmark$ & $\checkmark$ \\
\hline \multirow{3}{*}{ Mature } & $\begin{array}{l}\text { Non- } \\
\text { reducing }\end{array}$ & $\mathrm{N} / \mathrm{A}$ & $\approx 15 \mathrm{kDa}$ & $\approx 16 \mathrm{kDa}$ & $\approx 16 \mathrm{kDa}$ \\
\hline & Reducing & $\approx 26 \mathrm{kDa}$ & $\approx 12 \mathrm{kDa}$ & $\approx 14 \mathrm{kDa}$ & $\approx 14 \mathrm{kDa}$ \\
\hline & $\begin{array}{l}\text { Crosslinked } \\
\text { (observed) }\end{array}$ & $x$ & $x$ & $\checkmark$ & $\checkmark$ \\
\hline \multirow{3}{*}{$\begin{array}{l}\text { High } \\
\text { molecular } \\
\text { size band } \\
\text { observed }\end{array}$} & $\begin{array}{l}\text { Non- } \\
\text { reducing }\end{array}$ & $\begin{array}{c}\checkmark \\
\text { (Faint } \\
\text { trace) }\end{array}$ & $\checkmark$ & $x$ & $x$ \\
\hline & Reducing & $x$ & $x$ & $x$ & $x$ \\
\hline & Crosslinked & $\checkmark$ & $\checkmark$ & $\checkmark$ & $\checkmark$ \\
\hline
\end{tabular}

$\begin{array}{ll}\checkmark & \text { Observed in Western blots } \\ \times \quad \text { Not observed in Western blots }\end{array}$ 

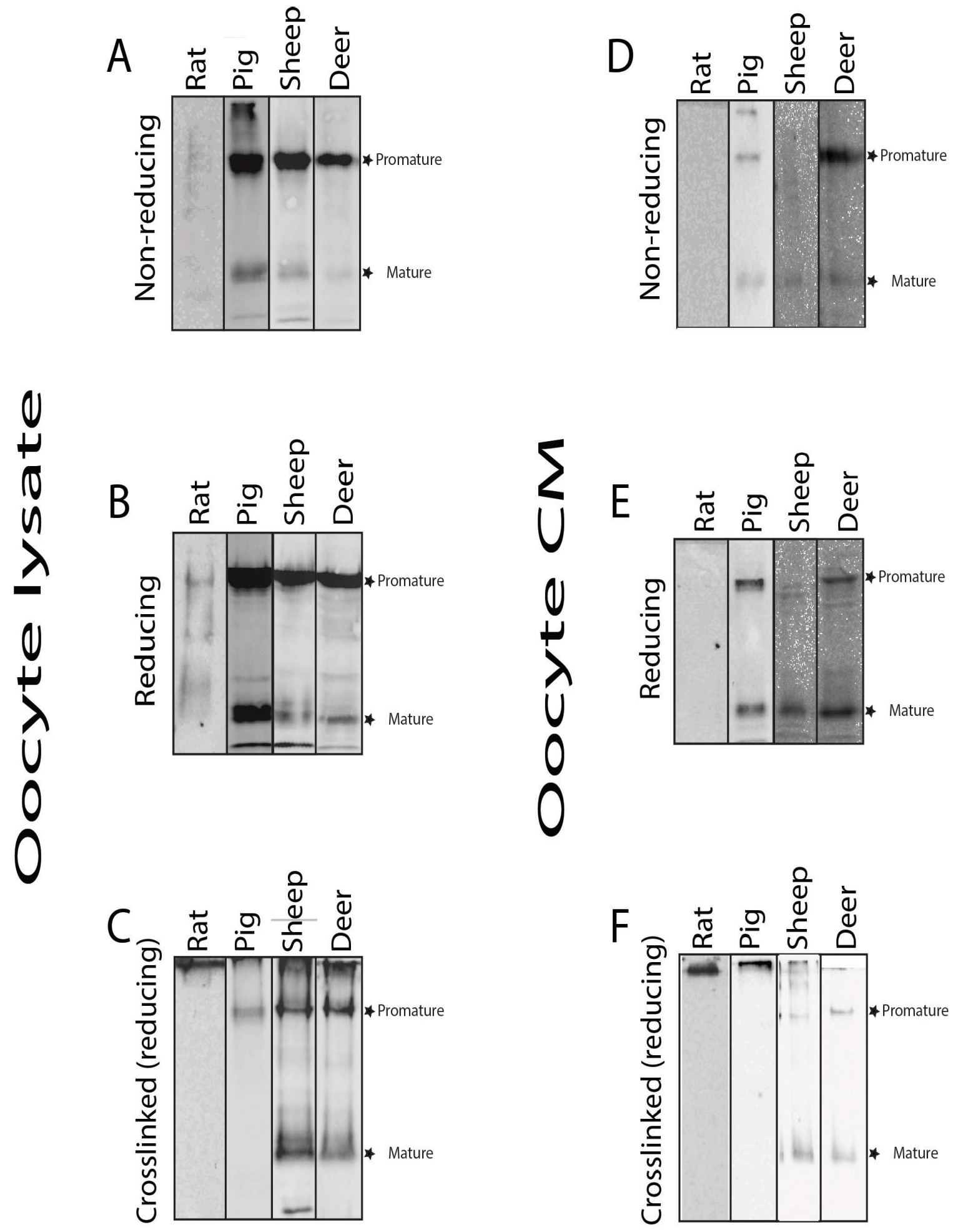

Figure 3.6: Allignment of GDF9 molecular forms found within and secreted four different litter size mammlian species; rat, pig, sheep, and deer. Oocyte lysate western blots of different mammalian species were gathered depending the treatment; (A) non-reducing, (B) reducing, (C) treated with crosslinking agent prior redcing treatment. Western blots of the conditioned media, where the oocyte were incubated for 18 hours are gathered based on the treatment; (D) non-reducing, $(E)$ reducing, $(F)$ treated with crosslinking agent prior redcing treatment. 


\subsection{Quantification of molecular forms of GDF9 across four mammalian}

species

The densities of the bands corresponding to the promature and mature forms of GDF9 under reducing conditions were compared against the mature band of the positive control (HEK293-expressed recombinant pig GDF9) as a corrected measure of protein quantification across all replicates in the four species. Band density was measured using Image J software (version 1.50i with Java 1.8.0_77 64-bit; National Institutes of Health (NIH)). The data were adjusted for background density and normalised against the positive control present in each blot.

In all species apart from the rat, there was more $(\mathrm{P} \leq 0.05)$ promature, than mature, GDF9 in oocyte lysates (Figure 3.7 A). However, there were no differences in the levels of promature and mature forms of GDF9 in oocyte lysates between species (Figure 3.7 A). On the other hand, no differences were observed between the secreted promature and mature forms within nor between species (Figure 3.7 B). The promature to mature GDF9 ratio was calculated to better illustrate the predominant forms located within, and secreted from, the oocyte. Statistical analysis of the promature to mature ratio did not illustrate any significance differences between species in the oocyte lysate and oocyte conditioned media (Figure $3.7 \mathrm{C}$ ). However in the sheep, pig and red deer at least, there appears to be a tendency for a higher proportion of the promature form to be present in oocyte lysate and a higher proportion of the mature form to be secreted into the media (Figure 3.7C).

Surprisingly, visualisation of the bands representing GDF9 from rat oocytes required a lengthy exposure time. As a result, the mature band of the positive control within each blot became over-saturated and unsuitable for normalisation purposes. Thus, quantification of rat-derived GDF9 forms was invalid. Also, a high variability in the density of the promature and mature bands, relative to the positive control, in the oocyte conditioned media of red deer was observed. 

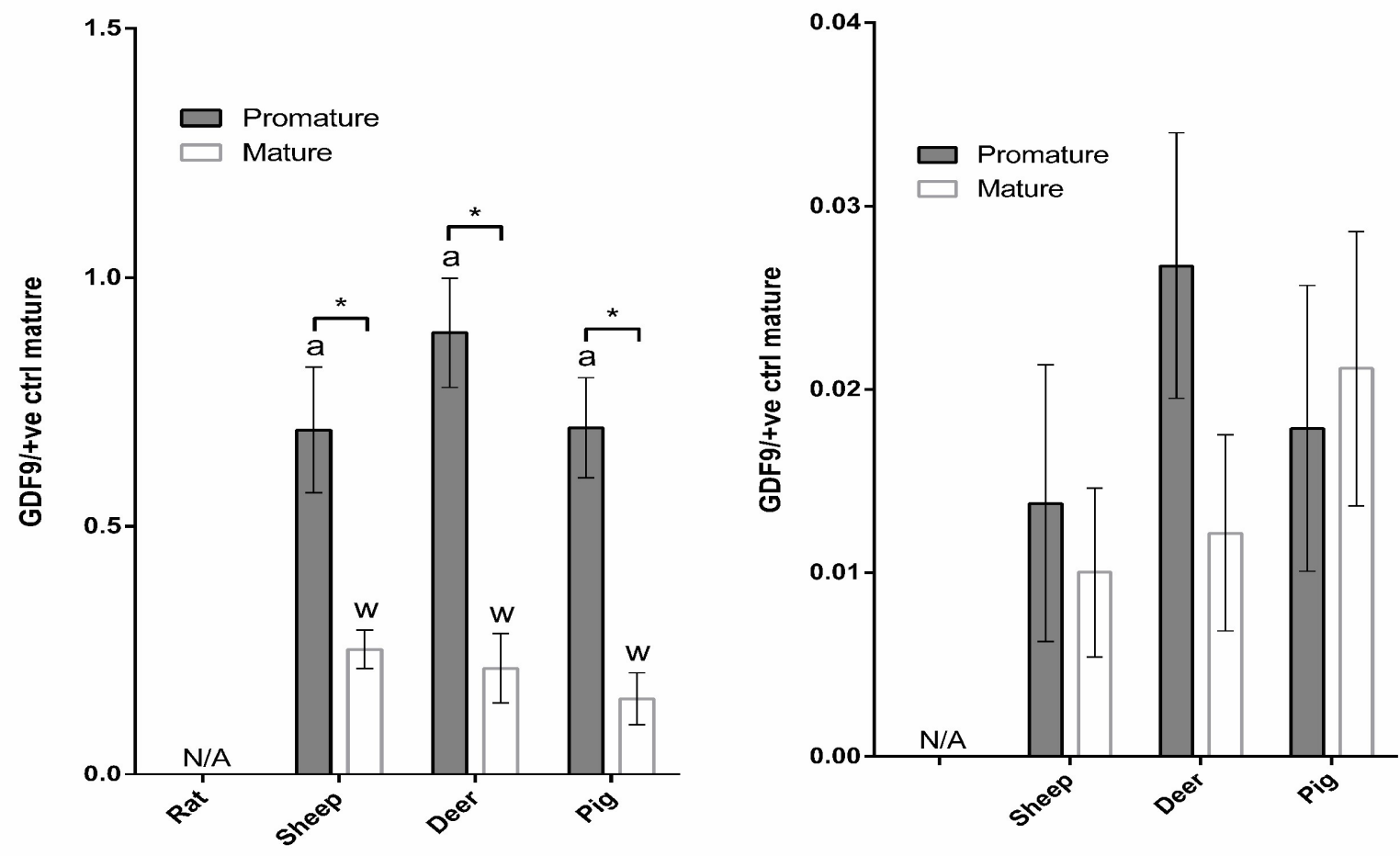

C

Ratio of promature:mature GDF9

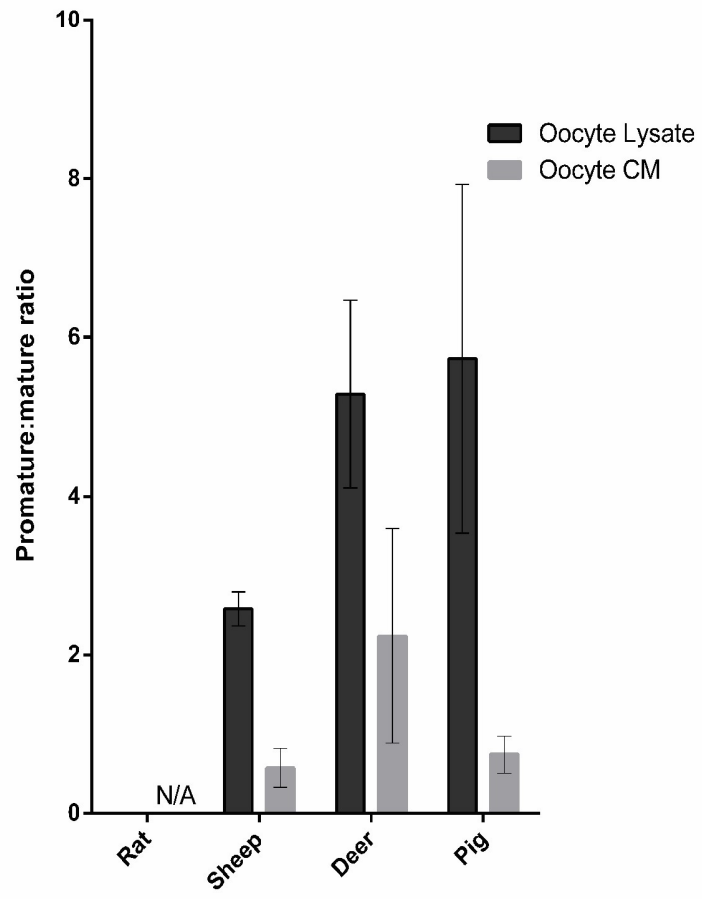

Figure 3.7: Densitometry analysis of GDF9 in mammalian species: band density of the reducing western blots replicates were measured, adjusted and normalised based on the number of oocyte used and the density of GDF9 positive control found in each blot. (A) representation of normalised densitometry data in oocyte lysates across the species (rat, sheep, deer and pig), (B) representation of normalised densitometry data in oocyte conditioned media across the species, and (C) representation of promature:mature ratio found within and secreted from oocyte across the species. The vertical error bars represent \pm SEM. Statistical analysis. Different letters above the columns for a given protein form indicate a significant difference between species ( $\mathrm{a}$ is used for the promature protein values and $\mathrm{w}$ is used for the mature protein values) $(P \leq 0.05)$. Brackets indicate significant differences between the promature and mature protein values within each species $\left({ }^{*}=P \leq 0.05\right)$. 


\subsection{Comparison between the antibodies MAB37A and MAB37G in identifying}

\section{GDF9 forms}

To compare the specificity and affinity of two different monoclonal antibodies (MAB37A and MAB37G), the molecular forms of GDF9 were identified in four mammalian species (rat, pig, sheep and red deer) by Western blotting. Western blots were prepared under reducing conditions using lysates from oocytes that had been incubated for 18 hours. MAB37A recognised the predicted molecular forms (i.e. promature and mature forms) in stringent conditions, whilst MAB37G detected a large range of products. The MAB37A antibody was able to identify GDF9 in 5\% blocking buffer at a concentration of $1 \mu \mathrm{g} / \mathrm{mL}$. However, MAB37G required a less stringent environment $(0.5 \%$ blocking buffer at a concentration of $2 \mu \mathrm{g} / \mathrm{mL}$; data not shown) for band detection. Both antibodies were able to recognise mature and promature forms of GDF9 with molecular size of $\approx 13-15$ $\mathrm{kDa}$ and $\approx 58-60 \mathrm{kDa}$ respectively (Figure 3.5). Whilst MAB37A has been shown to be able to recognise rat GDF9 in other studies (Lin et al., 2012), it was unsuccessful in detecting either form of rat GDF9 in this study (Figure 3.5A). Conversely, whilst MAB37G did on occasion recognise both the promature and mature forms of rat GDF9, however it did not recognise the HEK293-expressed recombinant pig mature form (Figure 3.5B). This, together with the high level of non-specific binding lead to the conclusion that the MAB37G antibody was unsuitable for this study.

A
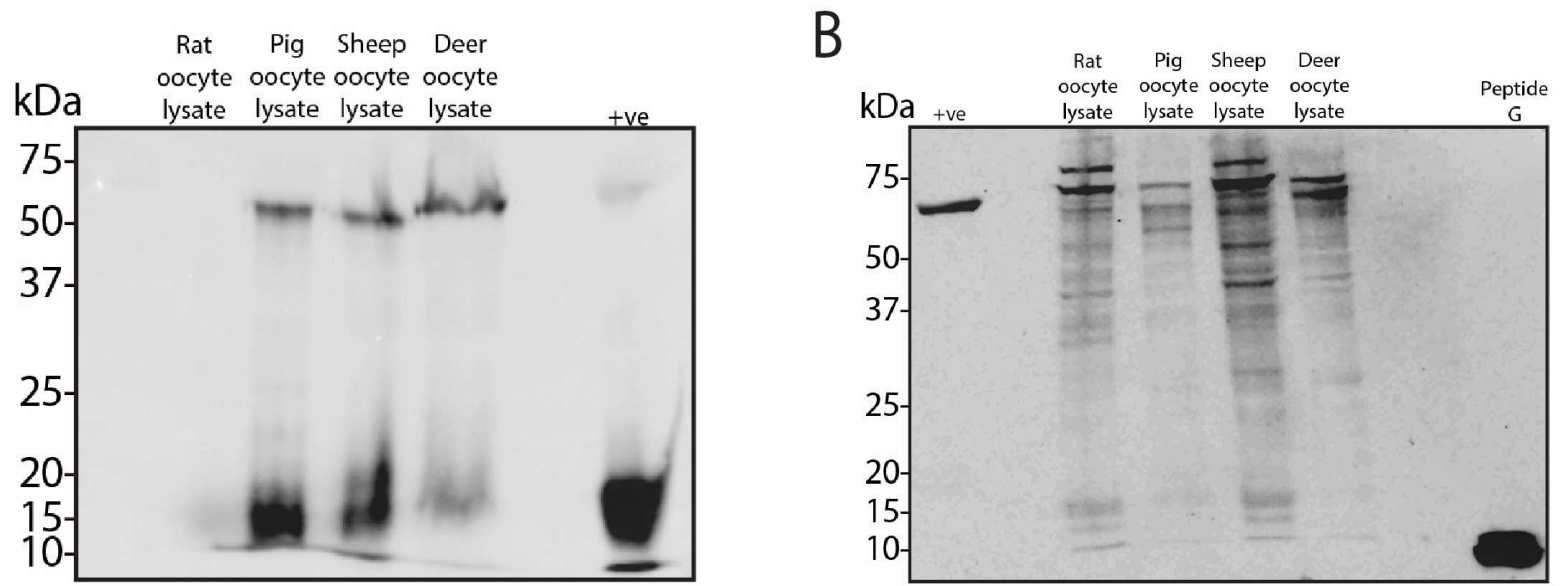

Figure 3.8: Comparison between MAB37A and MAB37G. (A) immune blot using MAB37A; lanes 2-5 are oocyte lysates of four mammalian species, lane 6 is the conditioned media of the recombinant pig GDF9. (B) immune blot using MAB37G; lane 1 is the conditioned media of the recombinant pig GDF9, lanes 3-6 are the oocyte lysates of four mammalian species, lane 8 is the peptide sequence that MAB37G was raised against. 


\subsection{Comparison between GDF9 and BMP15 molecular forms found within}

\section{the oocyte across the species}

To ensure that no heterodimers of GDF9 and BMP15 existed, comparisons between the molecular forms were performed by Western blotting under reducing conditions using pools of 100 oocytes from rats, pigs, sheep and red deer that were incubated for 18 hours. The blot was firstly incubated with MAB61A to identify BMP15 across the species and then stripped and re-probed with MAB37A to identify GDF9.

The dominant molecular forms of BMP15 found were promature and mature forms at molecular sizes of $\approx 50 \mathrm{kDa}$ and $\approx 15 \mathrm{kDa}$ respectively. The rat oocytes did not indicate any bands that corresponded to either the promature or mature forms (Figure 3.9 A). The pig oocytes illustrated a strong band corresponding to the promature form, whereas the mature band was faint (Figure 3.9 A). The sheep oocytes indicated a strong promature band with no observation of the mature form (Figure 3.9 A). The red deer oocytes exhibited a strong promature band and a faint mature band (Figure 3.9 A).

In terms of GDF9, similar forms found in BMP15 were observed as discussed previously. Namely the promature and mature forms at molecular sizes of $\approx>50$ $\mathrm{kDa}$ and $\approx \geq 15 \mathrm{kDa}$. The rat oocyte indicated a strong signal for the mature form, as well as other bands at $\approx 25$ and $40 \mathrm{kDa}$. The $40 \mathrm{kDa}$ band may correspond to a homodimer of GDF9 in oocytes after 18 hours incubation (Figure 3.9 B).

The inability to identify BMP15 in rat oocyte is likely due to insufficient numbers of oocytes used. Previous literature indicates that BMP15 levels are extremely 

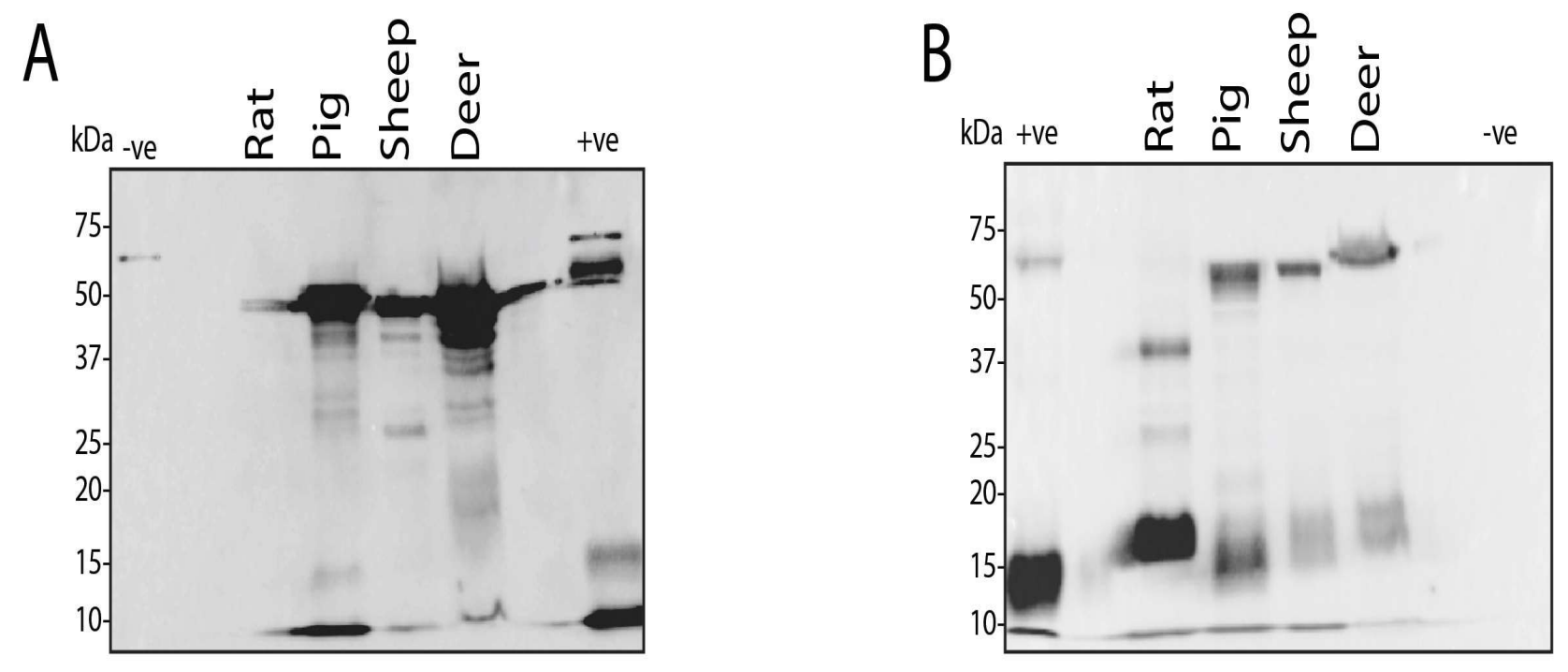

Figure 3.9: Comparison between GDF9 and BMP15 molecular forms found within oocyte lysate mammalian species with different litter sizes. (A) western blot incubated with MAB61A to identify BMP15, (B) stripped western blot in (A) incubated with MAB37A to identify GDF9. Each blot has in lane 1: HEK 293 producing pig GDF9 as positive control, lane 3-6: 00cyte lysates after 18 hours incubation, lane 8: HEK 293 producing pig BMP15 as negative control.

low (Crawford \& McNatty, 2012). Moreover, stripping a blot may result in low level of proteins being therefore it is possible that a previously identified rat promature GDF9 was removed from the blot. Finally, the comparisons of lysates between freshly collected oocytes and those incubated for 18 hours suggests that the levels and forms of GDF9 and BMP15 may change with time in culture.

\subsection{Bioactivity of recombinant pig GDF9 to BMP15}

To test the biological activity of recombinant pig GDF9 and BMP15, methyl- ${ }^{3} \mathrm{H}-$ thymidine incorporation bioassays were performed on sheep GC after addition of the recombinant proteins. Firstly, the synergistic effects of these recombinants proteins were tested and then the effects of different ratios of these proteins were tested.

The addition of recombinant pig GDF9 and BMP15 alone or in combination increased $(\mathrm{P}<0.05)$ the proliferation rate of the sheep GC's (Figure 3.10). However, adding both recombinant pig GDF9 and BMP15 together did not 


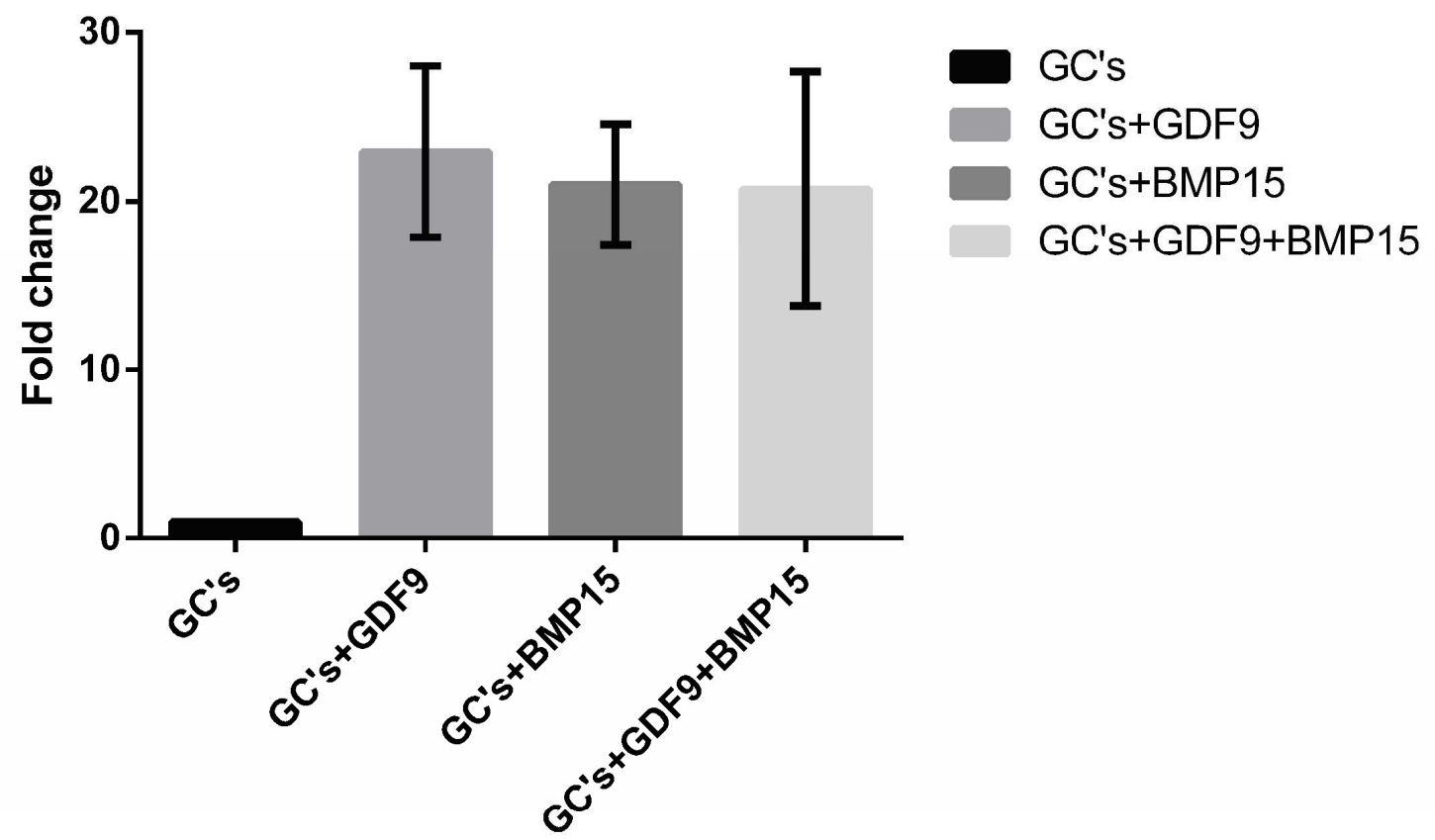

Figure3.10: The effect of adding GDF9 and BMP15 pig recombinant on sheep granulosa cells proliferation. The measurement of meth$\mathrm{yl}-3 \mathrm{H}$-thymidine uptake were adjusted for the background noise and normalised by dividing on the measurement of GC's alone. Each treatment was replicated three times. GC's: is 20,000 viable sheep granulosa cells incubated alone. GC's+GDF9: is 20,000 viable sheep granulosa cells incubated with $1 \mu \mathrm{l}$ of the conditioned media of HEK 293 producing pig GDF9. GC's+BMP15: is 20,000 viable sheep granulosa cells incubated with $1 \mu \mathrm{l}$ of the conditioned media of HEK 293 producing pig BMP15. GC's+GDF9+BMP15: is 20,000 viable sheep granulosa cells incubated with $1 \mu \mathrm{l}$ of the conditioned media of HEK 293 producing pig GDF9 and $1 \mu$ l of the conditioned media of HEK 293 producing pig BMP15.

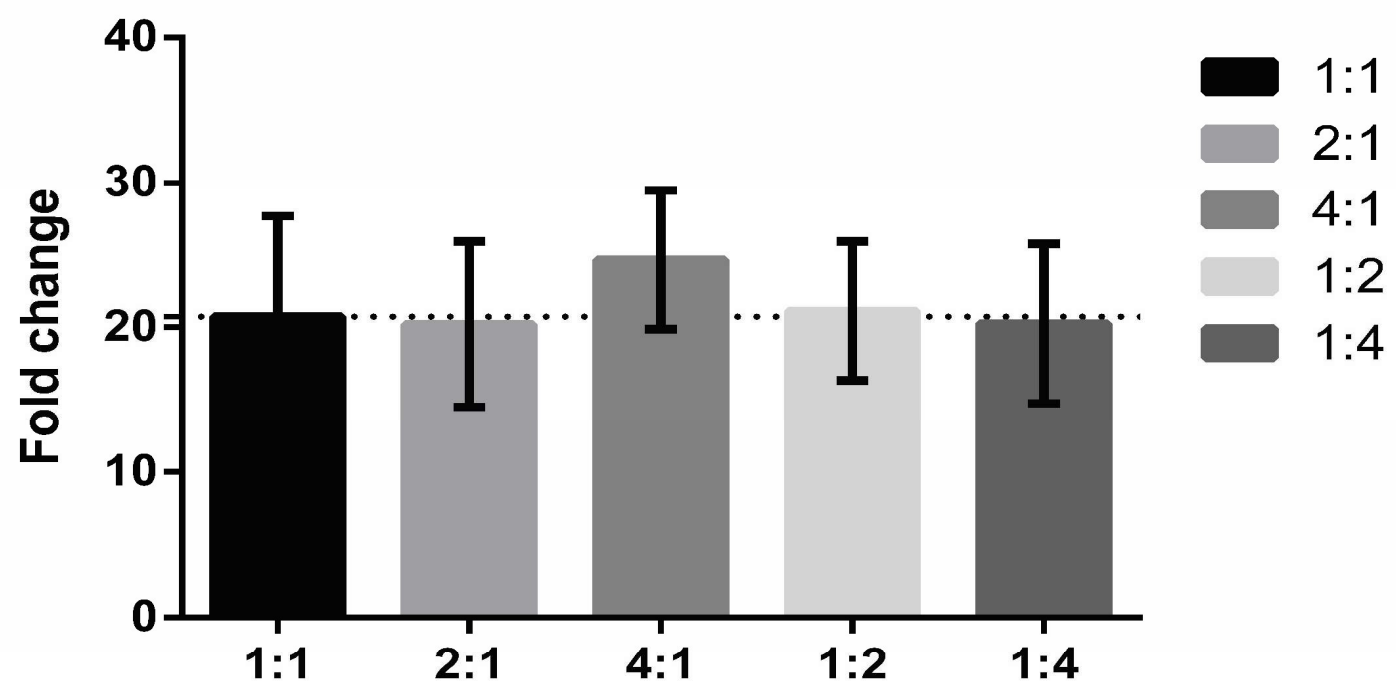

GDF9:BMP15

Figure3.11: The effect of adding different ratios of GDF9 to BMP15 pig recombinants on sheep granulosa cells proliferation. The measurement of methyl-3H-thymidine uptake were adjusted for the background noise and normalised by dividing on the measurement of the GDF9:BMP15 1:1 ratio. Each treatment was replicated three times. (1:1): is 20,000 viable sheep granulosa cells incubated with $1 \mu$ l of the conditioned media of HEK 293 producing pig GDF9 and $1 \mu$ l of the conditioned media of HEK 293 producing pig BMP15. . (2:1): is 20,000 viable sheep granulosa cells incubated with $2 \mu \mathrm{l}$ of the conditioned media of HEK 293 producing pig GDF9 and $1 \mu$ of the conditioned media of HEK 293 producing pig BMP15. (4:1): is 20,000 viable sheep granulosa cells incubated with $4 \mu$ lof the conditioned media of HEK 293 producing pig GDF9 and $1 \mu \mathrm{l}$ of the conditioned media of HEK 293 producing pig BMP15. (1:2): is 20,000 viable sheep granulosa cells incubated with $1 \mu$ l of the conditioned media of HEK 293 producing pig GDF9 and $2 \mu$ of the conditioned media of HEK 293 producing pig BMP15. (1:4): is 20,000 viable sheep granulosa cells incubated with $1 \mu$ l of the conditioned media of HEK 293 producing pig GDF9 and $4 \mu$ l of the conditioned media of HEK 293 producing pig BMP15. 
increase levels of proliferation over and above those of GCs treated with recombinant pig GDF9 or BMP15 alone (Figure 3.10).

The addition of recombinant pig GDF9 and BMP15 at different ratios (GDF9:BMP15 ratios of 2:1, 4:1,1:2, and 1:4) did not significantly alter the proliferation rate compared to that after the addition of a 1:1 ratio of recombinant pig GDF9:BMP15 (Figure 3.11). Although no statistical significance was identified, there appeared to be a trend whereby adding more GDF9 to BMP15 slightly increased the proliferation rate however further testing is required due to the variability of the results.

\subsection{Neutralisation of the bioactivity of recombinant pig GDF9 to BMP15} using GDF9 and BMP15 antibodies.

To test the ability of the antibodies to detect the biologically-active forms of GDF9 and BMP15, neutralisation experiments using antibody were performed whereby antibodies were used to block the proliferation of, granulosa cells following the treatment of recombinant pig GDF9 or BMP15. Firstly, tests on the proliferation rate of granulosa cells in all of the mammalian species included in this study were undertaken to determine responses to recombinant pig GDF9 or BMP15. The sheep granulosa cells showed the best response to a low amount (1 $\mu \mathrm{L}$ ) of the recombinant pig GDF9 and BMP15 (data not shown) and thus sheep granulosa cells were used for the neutralisation experiments.

Thus, 20,000 viable sheep granulosa cells were incubated with recombinant pig GDF9 or BMP15 in the presence or absences of their respective antibodies (MAB37A and MAB37G for GDF9; MAB61A and MAB61B for BMP15). A concentration of $10 \mu \mathrm{g} / \mathrm{mL}$ of each antibody was used. Two neutralisation approaches were tested: no pre-incubation of the antigen and antibody; and preincubation of the antigen and antigen. The results then were adjusted for the background by removing the effect of the methyl- ${ }^{3} \mathrm{H}$-thymidine on media alone, then standardised against their corresponding control. 


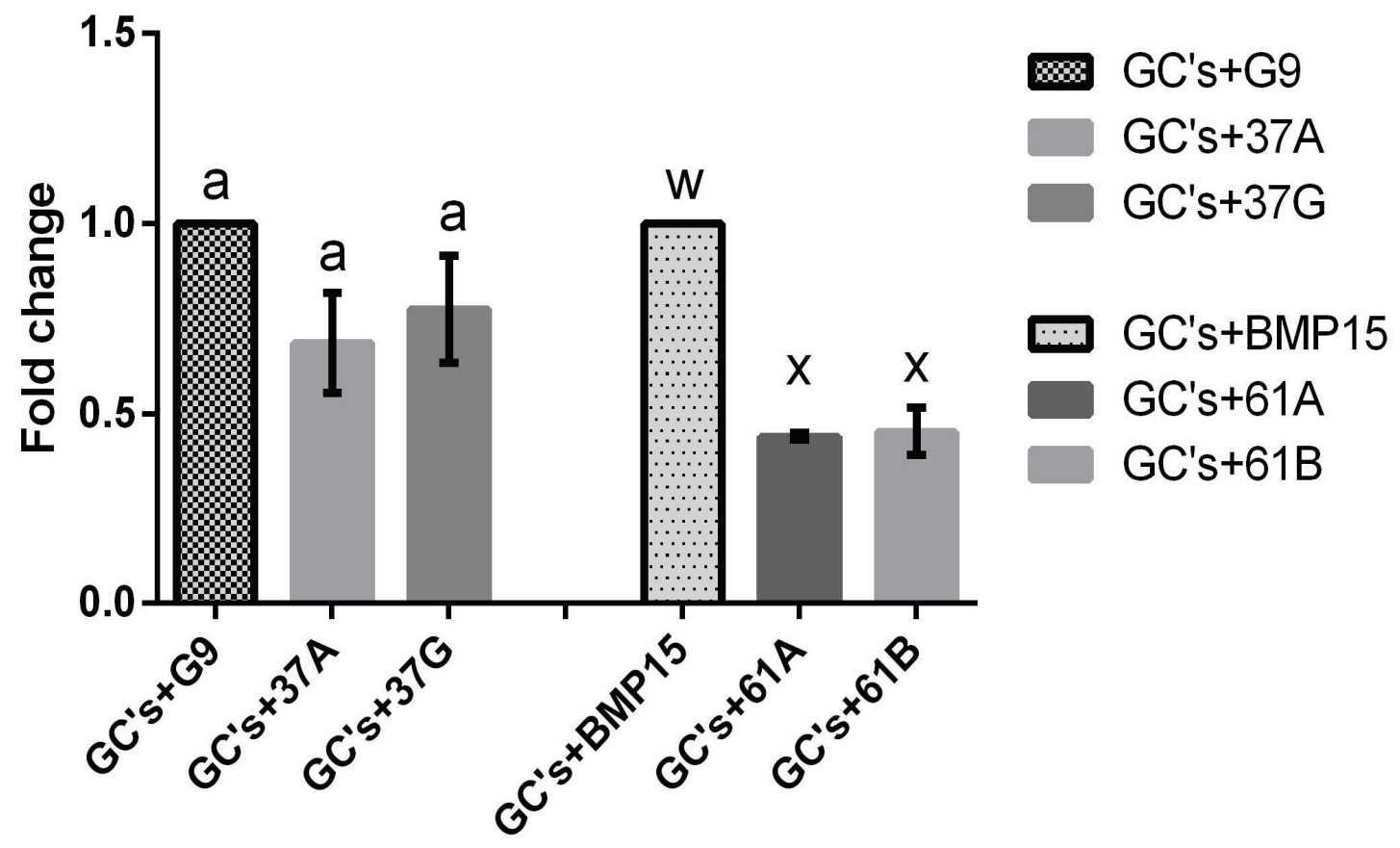

B

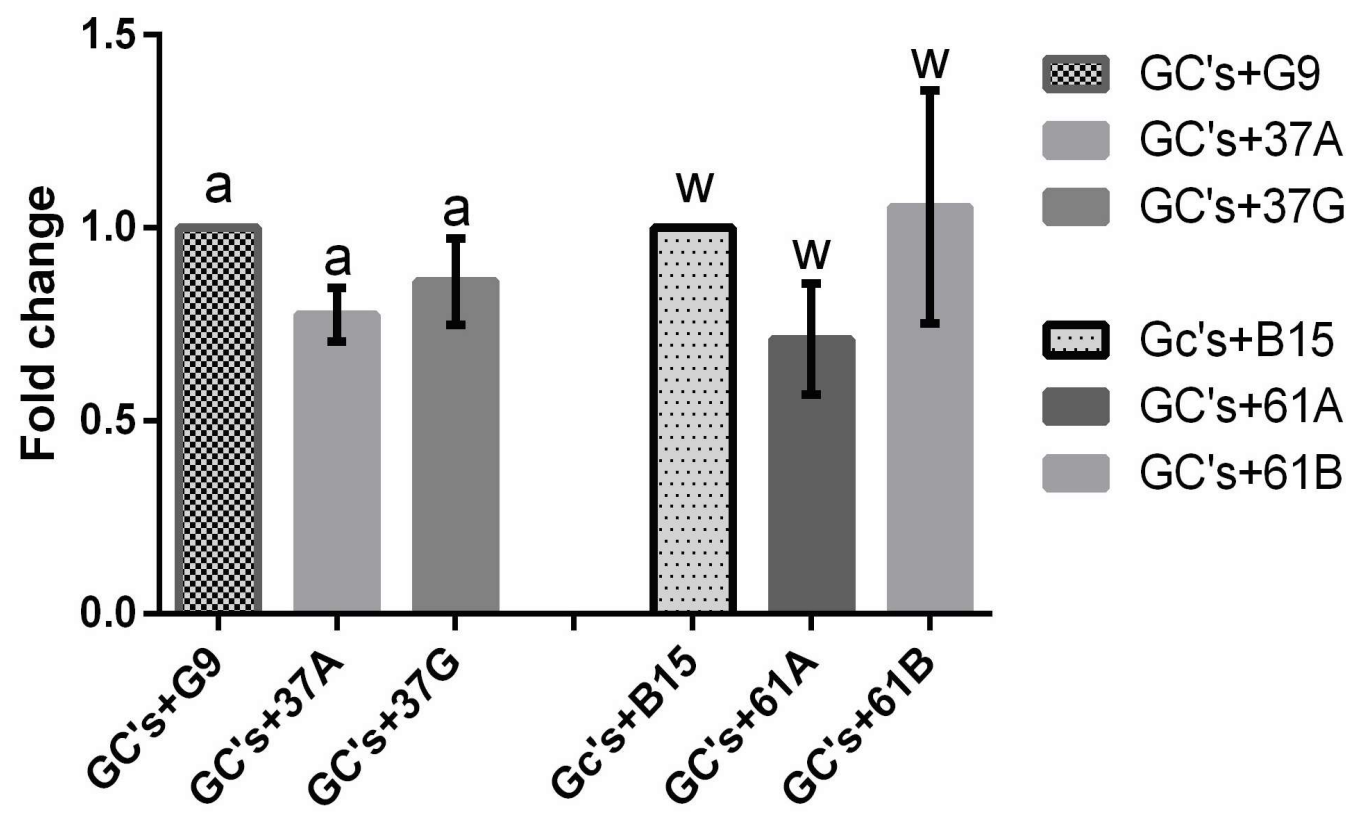

Figure 3.12: Neutralising bioactive recombinant GDF9 or BMP15 using MAB: Sheep granulosa cells were incubated with either $1 \mu \mathrm{l}$ of the conditioned media of HEK 293 producing pig GDF9 or $1 \mu$ l of the conditioned media of HEK 293 producing pig BMP15 to measure the methyl-3H-thymidine uptake. (A) The granulosa cells were incubated with the recombinant protein (GDF9 or BMP15) and its designated monoclonal antibody (MAB37A \& MAB37G for GDF9, MAB61A and MAB61B for BMP15). The fold change of the different treatment was standardised relative to its positive control (fold change of granulosa cells with recombinant protein). (B) is similar design to (A) except that the antibody and recombinant protein were pre-incubated and centrifuged, where the supernatant collected to be incubated with granulosi cells. Letter a above the error bars represent different data set than letters $w$ and $x$. The letter $w$ is statistically different $(P<0.05)$ than those 
The addition of MAB37A or MAB37G to the sheep granulosa cells treated with recombinant pig GDF9 did not significantly reduce the proliferative effects of GDF9, regardless of pre-incubation status (Figure 3.12 A). However, the addition of MAB61A or MAB61B to sheep granulosa cells treated with recombinant pig BMP15 did decrease $(\mathrm{P}<0.05)$ the proliferation rate when the antibody was not pre-incubated with the antigen (Figure $3.12 \mathrm{~A}$ ). Interestingly, this effect was not observed with either MAB61A or MAB61B when pre-incubated with recombinant pig BMP15 (Figure 3.12B). 


\section{Chapter 4: Discussion}

\section{1: The molecular forms of GDF9 present within or secreted from oocyte of different mammalian species with different litter sizes (rat, pig, sheep, and red deer)}

A series of Western blots were performed to determine the molecular forms of GDF9 present within and secreted from the oocytes of mammalian species with different litter sizes. The novelty of this study was to compare the molecular forms of pig- and red deer-derived GDF9 to that already identified in rats and sheep (Lin et al., 2012). The results from this study revealed that the promature and mature forms of GDF9 were the dominant forms found within oocyte lysates of all species. Moreover, in regards to the forms secreted from the oocyte, the promature and mature forms were also detected in pigs, sheep and red deer. Unfortunately the levels of secreted GDF9 were undetectable in rats. The usage of non-reducing and reducing conditions suggested that some of the mature GDF9 had been cleaved from the proregion but remained non-covalently associated to the proregion. This was evident by the increase in the density of the mature band under reducing conditions, compared to that observed under non-reducing conditions, in all the species tested. Incubating the samples with a crosslinking agent prior to processing the samples under reducing conditions did not provide any evidence of GDF9 homo- or hetero-dimers in any of the species tested in this study. On the other hand, a high molecular size band was identified across all species when both oocyte lysates and conditioned media samples were incubated with the crosslinking reagent.

Even though the Western blot signal detected in rat oocytes was faint, promature and mature forms of GDF9 were detected under reducing conditions (Figure 3.2 B). The mature form of rat GDF9 was $\approx 26 \mathrm{kDa}$ in size. Previous studies using recombinant rat GDF9 illustrated the likelihood of glycosylation in rat GDF9 due to a decrease in protein size being observed after treatment with $\mathrm{N}$-glycosidase $\mathrm{F}$ (Hayashi et al., 1999, Hsueh et al., 2000). The size of the presumptive 
glycosylated recombinant rat mature form was a similar size to that of the native rat mature form in this study which suggest that the native form of rat GDF9 is also glycosylated at the $\mathrm{N}$-terminal end, as there is only one glycosylation site on the mature form of GDF9 (McPherron \& Lee, 1993, Johnson, Dickens, Kent, \& Giles, 2005). Under non-reducing conditions, the GDF9 forms were more difficult to detect and only a faint band that corresponded to the promature form was identified suggesting that a significant form may be that of cleaved promature GDF9 whereby the mature form remains associated with its proregion (Figure 3.2 A). Adding a crosslinking agent revealed that bands previously identified in non-crosslinked samples were no longer visible. Instead, a high molecular size band was visible suggesting GDF9 may form as multimers. Any possible secreted forms of rat GDF9 were unable to be visualised under either non-reducing or reducing conditions, suggesting that if present, GDF9 forms were below the detection limit of my Western blotting procedure. On the other hand, treatment with a crosslinking agent illustrated a high molecular size band similar to that observed in the oocyte lysate under non-reducing conditions (Figure 3.2 C). These results may indicate that mature GDF9 in rats is glycosylated and has an affinity for associating with other proteins, or possibly forming promature dimers. The effects of glycosylation might better reflect the solubility of the mature GDF9 in rats, hence increasing its bioactivity. An earlier study examining the glycosylation sites of $\alpha$-galactosidase found that the number and site of glycosylations reflected the solubility, stability, and even folding properties and concluded that this would lead to a more bioactive protein (Ioannou et al., 1998). Although it is important to note that there was no evidence of homo- or heterodimer forms of mature rat GDF9

Lysates of, and secretions from, pig oocytes revealed that GDF9 was present in both promature and mature forms under reducing conditions (Figure $3.3 \mathrm{~B}$ ). Similar to the rat, non-reducing conditions revealed the appearance of a high molecular size band of GDF9 from within oocyte lysates and secreted media (Figure $3.3 \mathrm{~A}$ ). Unlike the rat, the mature form of pig GDF9 was evident under non-reducing conditions suggesting that the mature form of pig GDF9 disassociates from its proregion and is present as a free mature form. The size of 
the mature form of pig GDF9 was $\approx 15 \mathrm{kDa}$, which is close to the size of the $\mathrm{N}$ glycosidase F-treated recombinant rat GDF9 (Hayashi et al., 1999, Hsueh et al., 2000), suggesting species differences in post-translational modifications of GDF9. Applying the crosslinking agent to pig oocyte lysates showed a similar high molecular size band as observed in rats, with faint traces of promature form of GDF9 (Figure $3.3 \mathrm{C}$ ). The secreted media of pig oocytes also indicated high molecular size bands however no promature and mature GDF9 forms were identified as in oocyte lysates (Figure $3.3 \mathrm{C}$ ). These results suggest that pig mature GDF9 is unglycosylated, which might suggested that the pig mature GDF9 has a reduced solubility (Ioannou, et al., 1998). On the other hand like the rat, pig GDF9 may also have a tendency to form multimer and promature dimers. It is possible that pig promature GDF9 is glycosylated, which might explain the higher molecular size of the promature form compared to rats. Therefore the promature or the non-covalently associated proregion-mature protein has better solubility and reflects its polyovulatory phenotype. Similarly, there was no evidence of GDF9 homo- or hetero- dimers in the pig.

A previous study by Lin et al., 2012 indicated that the molecular forms of GDF9 within sheep oocyte lysates were the promature and mature forms, whereas the conditioned media contained only the mature form. As represented in Figure 3.4, sheep oocyte lysates and secreted media showed both molecular forms of GDF9 under both non-reducing and reducing conditions (Figure 3.4 A\&B). However, treatment of sheep samples with a cross-linking reagent showed different results to those shown in rat and pig oocytes. In a previous study using recombinant ovine GDF9, crosslinking resulted in multiple forms including the mature form, homo-dimers and multimers of GDF9 (Edwards et al., 2008). In this study, the crosslinking of native sheep GDF9 illustrated the appearance of a high molecular size band in oocyte lysate and conditioned media, as well as the promature and mature forms (Figure 3.4 C). This finding could suggest that post-translational modifications of GDF9 is different between species. These differences may reflect differences in the number of glycosylated sites as the size of the promature and mature differ between sheep and rat. Or these differences may reflect difference in the sites of glycosylation, particularly as the pig and sheep do not differ 
significantly in terms of the promature and mature molecular size. This might affect the protein stability and bioactivity as it was determined in $\alpha$ galactosidase that glycoslation sites contributed to bioactivity, where in GDF9 case could reflect the significant different ovulatory phenotype between these species (Ioannou et al., 1998). Also, it is possible that unprocessed promature, or non-covalently bound proregion-mature act as a chaperone and is important for the bioactivity of GDF9 hence the differences in litter size between the species. Similar to the rat and pig, homo- or hetero- dimers of GDF9 were not detected in oocyte lysates and conditioned media of sheep.

Interestingly, the forms of GDF9 detected within and secreted from red deer oocyte were similar to that observed in sheep across all treatments. The promature and mature forms of GDF9 were the predominant forms under both non-reducing and reducing conditions. The slightly higher molecular size of red deer GDF9 compared to that of the pig and sheep (Figure $3.5 \mathrm{~A} \& \mathrm{~B}$ ) suggests different glycosylation sites between species. Similarly, incubating samples with a crosslinking agent resulted in the formation of a multimer form in both oocyte lysates and oocyte conditioned media, together with traces of promature and mature forms (Figure 3.5 C). As suggested in the sheep, it is possible that the post-translational modifications present in red deer promature and mature GDF9 forms decreases the potency of GDF9 promature dimerisation, and decrease the efficiency of the proregion's predicted role to act as a chaperone for the mature protein.

Using the secreted media of HEK-293 cells transformed with pig GDF9 as the positive control, similar molecular sizes of the native GDF9 promature and mature forms were observed between non-reducing and reducing conditions in pig, sheep and red deer. However, applying the crosslinking reagent on the recombinant protein revealed the formation of a possible homodimer that was not identified in any of the native forms. This finding could suggest that GDF9 in its native form could bind to other proteins (represented by the high molecular size band identified) which it has a higher affinity to and form multimers, or 
recombinant forms of GDF9 secreted from HEK-293 are not representative of the native forms.

As noted above, the crosslinking studies indicated differences between the secreted forms of GDF9 in the pig, compared to the sheep and red deer. Crosslinked secretions from rat and pig oocytes revealed the absence of promature and mature forms and the appearance multimer forms. This is possibly due to dimerisation of promature forms or associations of GDF9 forms with other TGF $\beta$ proteins. However, cross-linked sheep and red deer samples still illustrated promature and mature forms of GDF9, which could suggest that GDF9 from species with a large litter size has an increased affinity for other similar proteins than species with a small litter size. Or that the glycosylation sites in species with larger litter sizes differ in term of site and/or number to those of species with small litter sizes. Alternatively, a molecular structure similar to the pro-cumulin synthesised by Mottershead et al. (2015) (i.e. a promature-mature GDF9 dimer) could be favoured in the rat and pig, which stimulates increased granulosa cell proliferation rate and improvements in oocyte quality.

\section{2: The relative amount of promature and mature GDF9 found within or} secreted from oocytes of different mammalian species with different litter size (rat, pig, sheep, and red deer)

For semi-quantitative analysis on the relative amounts of promature and mature GDF9 forms within or secreted from oocytes of rats, pig, sheep and red deer, bands from Western blots that represent samples under reducing conditions were analysed. To minimise inter-blots variation, the exposure time for collecting band densitometry results were optimised such that densitometry results did not reach saturation levels in any replicate. It should be noted that the densiometry results from the faint bands observed from rat oocytes were not included due to the extended exposure times resulting in the positive controls reaching saturation levels before the appearance of any molecular forms of GDF9. 
The statistical analysis of the densitometry data obtained revealed that levels of promature GDF9 was significantly higher than the levels of the mature form in any species tested (Figure 3.7 A). However, inter-species comparisons of the levels of either promature or mature forms of GDF9 did not illustrate any significant difference between species (Figure 3.7 A). Moreover, a comparison between the molecular forms of secreted GDF9 from the oocyte did not indicate any significant inter-species differences (Figure 3.7 B).

Though a high variability was observed that reduced the statistical power, there is possible tendency, at least in the sheep and pig that the levels of the promature GDF9 form was higher within the oocyte whilst the mature GDF9 form was predominant as the secreted form. This may be explained through a possible role of the soluble proregion, facilitate the transportation of poorly soluble bioactive mature GDF9 (Mueller \& Nickel, 2012).

A study by Crawford and McNatty (2012) illustrated that levels of GDF9 mRNA was found to be associated with ovulation rate phenotype, wherein species with larger litter sizes (rat, pig and sheep) were higher than that with smaller litter sizes (red deer). It is possible that protein levels did not concur with GDF9 mRNA levels due to the limitations of Western blotting; as the antibody recognition was likely different among the species. Alternatively, these results may also indicate that GDF9 protein levels do not follow that of mRNA expression levels. It is possible also that levels of GDF9 protein is not essential as the ability of secreted molecular structure to adapt to its environment as it has been shown that crosslinking secreted forms of red deer GDF9 was not as intense as high ovulation rate species. Another theory is that the post-translational mechanisms are species-specific, which could alter the efficacy of the final GDF9 product. Future studies to determine the phosphorylation or glycosylation sites of GDF9, and their implications, on GDF9 function, in the different species are warranted. The GDF9 protein has three potential sites of glycosylation on the promature region and one potential glycosylation site on the mature region (McPherron \& Lee, 1993). This theory may explain the slightly higher molecular size of red deer 
GDF9 and its inability to be crosslinked as efficiently as the GDF9 from the other species included in this study.

\section{3: The ability of the monoclonal antibodies to bind biologically-active}

\section{GDF9 or BMP15}

To indicate the ability of different monoclonal antibodies to detect the biologically active forms of GDF9 or BMP15, sheep granulosa cell proliferation bioassays were performed whereby cells were incubated with recombinant pig GDF9 or BMP15 in the absence or presence of their respective antibodies. It had been determined that the recombinant GDF9 and BMP15 used were biologicallyactive and stimulated granulosa cells proliferation (Figure 3.10). Two methods of neutralising the antibodies were tested; immediate incubation or preincubation.

Previous studies used different sets of MAB for GDF9 and MAB61A for BMP15 to neutralise a recombinant rat/ovine GDF9 and rat/ovine BMP15 indicated that the proliferation rate of granulosa cells decreased significantly compared to their control (McIntosh et al., 2008, Lin et al., 2012). The results obtained from neutralisation study indicated that only MAB61A and MAB61B were able to neutralise the biologically active form in the recombinant pig BMP15 preparation, whereby the proliferation rate of granulosa cells significantly decreased compared to its control (Figure 3.10). However, neutralising GDF9 using both MAB's did not alter the proliferation significantly compared to its control, which was granulosa cells with recombinant GDF9, regarding the incubation status (Figure 3.10).

Compared to Lin et al. (2012) and McIntosh et al. (2008) studies, which successfully neutralised bioactive forms GDF9 using MAB47B, in this study MAB37A and MAB37G did not. All of these MAB were synthesised against ovine mature GDF9 and a peptide sequence that is found within the mature region. On the other hand, neutralising BMP15; using MAB61A and MAB61B, which were synthesised against a sequence found within the mature region, illustrated a 
decrease in the proliferation similar to that found on earlier studies (McIntosh et al., 2008, Lin et al., 2012). It is noteworthy that the using pig recombinant GDF9/BMP15 instead of ovine/rat recombinant GDF9/BMP15 could explain the possible different in the neutralisation responses. As there was no study that performed a similar experiment using pig recombinants, these results stand to be corrected by further testing; specifically testing neutralisation of recombinant pig GDF9 using MAB47B, and neutralising ovine GDF9 using MAB37A and 37G to determine if it is species differences or antibody binding difference. 


\section{4: Study conclusions}

Studying the molecular forms of GDF9 across the four different mammalian species included in this study showed that regardless of different litter sizes, the forms of GDF9 observed within oocytes were similar. Whilst the forms of GDF9 secreted from pig, sheep, and red deer oocytes were also similar to each other and that within their oocyte, the secreted forms of rat GDF9 were undetectable. Pre-absorbing the MAB with recombinant ovine GDF9 illustrated the specificity of MAB37A towards GDF9 of the bands identified, which is determined by the disappearance of the identified bands.

Applying a crosslinking agent to oocyte lysate or conditioned media samples did not provide any evidence of the presence of dimers in any species. However, the cross-linking of secreted forms of pig GDF9 demonstrated the appearance of a high level molecular size form in combination with the disappearance of the promature or mature forms. In contrast, the cross-linking of secreted forms of sheep and red deer GDF9 resulted in the appearance of a high molecular size form together with the promature and mature forms. This point of difference may suggest that a promature dimer is more common in the pig and has an important role on regulating ovulation rate. Moreover, differences in posttranslational modifications, specifically glycosylation, may exist between species with large and small litter-sizes. It is suggested as a result of the different molecular size noted on the mature form of rats GDF9, which is thought to be glycosylated, compared to other species, and the different molecular sizes identified of the promature form across the species. Glycosylation could possibly affect the solubility, stability and bioactivity of the protein, which might partially explain the phenotypic difference across the species. These modifications may either inhibit or facilitate the dimerisation of the promature and mature forms of GDF9.

The mRNA expression levels of GDF9 as observed previously (Crawford \& McNatty, 2012) was not apparent when Western blotting was used to measure 
proteins levels of GDF9 within an oocyte. It was noted that red deer has low levels of GDF9 mRNA expression compared to sheep and pig. However, densitometry analyses of the detected levels of GDF9 protein across these species were not different. Also, the densitometry analyses illustrated that all species measured in this study had higher levels of promature, than mature, GDF9 within the oocyte.

Finally, pig recombinant GDF9 and BMP15 proved to be biologically active, however neutralising recombinant pig GDF9 using MAB37A and 37G that target the mature form did not show a significant decrease on the proliferation rate of granulosa cells. This might illustrate that pig recombinant GDF9 affinity towards MAB's is different than that to ovine recombinant GDF9. However, neutralising recombinant pig BMP15 using MAB61A and 61B that target mature form illustrated significant decrease on the proliferation rate of granulosa cells. Further investigation by neutralising against the promature form versus neutralising only mature form could support the hypothesis that GDF9 promature has bigger role than just being a chaperon for mature form, or illustrate there is possible species difference between the mature forms of GDF9. 


\section{5: Future Directions}

The findings in this study raised questions regarding the role of promature GDF9 in forming non-covalent associations with the mature form of GDF9. Moreover, species differences in post-translational modifications of GDF9 need to be better defined.

Studies involving the isolation or manufacture of pure preparations of promature and mature GDF9 form would aid in explaining the role each form play and the implications of their interactions. In particular, adding these preparations to a granulosa cell proliferation assay would provide a clearer picture of the differences found, when crosslinking agent were applied, among the studied species, which might indicate that they differ at post-translational modification, number or location. Also, this experiment will illustrate which molecular form is more biologically active. Moreover, if we applied crosslinking agent on the purified forms and illustrated later that homo- or hetero-dimers promature-mature forms exist and do increase the granulosa cells proliferation rate, then a stronger argument can be made supporting the effect of the dimerization of native forms on oocyte health and ovulation rate.

Interestingly, incubating oocytes for 18 hours resulted in the appearances of multiple bands in oocyte lysates. Further investigations on these differences are suggested; possibly comparing between the conditioned media, which illustrate the molecular forms secreted, and the oocyte lysates to illustrate the modifications that occurred within the oocyte at the different time intervals.

Finally, the synergistic effects of GDF9 and BMP15 have been demonstrated in various studies (Mottershead et al., 2012, Lin et al., 2012) however results from this study did not conform to these. Further testing is needed to illustrate if that difference can be obtained using pig recombinant proteins. 


\section{References}

Al-Musawi, S., Walton, K., Heath, D., Simpson, C., \& Harrison, C. (2013). Species Differences in the Expression and Activity of Bone Morphogenetic Protein 15. Endocrinology, 154(2), 888-899. http://dx.doi.org/10.1210/en.2012$\underline{2015}$

Burgess, R. and Deutscher, M. (2009). Guide to protein purification. Amsterdam: Elsevier/Academic Press.

Chang, H., Brown, C., \& Matzuk, M. (2002). Genetic Analysis of the Mammalian Transforming Growth Factor- $\beta$ Superfamily. Endocrine Reviews, 23(6), 787823. http://dx.doi.org/10.1210/er.2002-0003

Crawford, J. and McNatty, K. (2012). The ratio of growth differentiation factor 9: Bone morphogenetic protein 15 mRNA expression is tightly co-regulated and differs between species over a wide range of ovulation rates. Molecular and Cellular Endocrinology, 348(1), pp.339-343.

Dong, J., Albertini, D., Nishimori, K., Kumar, T., Lu, N. and Matzuk, M. (1996). Growth differentiation factor-9 is required during early ovarian folliculogenesis. Nature, 383(6600), pp.531-535.

Edwards, S., Reader, K., Lun, S., Western, A., Lawrence, S., McNatty, K. and Juengel, J. (2008). The Cooperative Effect of Growth and Differentiation Factor-9 and Bone Morphogenetic Protein (BMP)-15 on Granulosa Cell Function Is Modulated Primarily through BMP Receptor II. Endocrinology, 149(3), pp.1026-1030.

Gilchrist, R., Lane, M. and Thompson, J. (2008). Oocyte-secreted factors: regulators of cumulus cell function and oocyte quality. Human Reproduction Update, 14(2), pp.159-177.

Griffith, D., Keck, P., Sampath, T., Rueger, D. and Carlson, W. (1996). Threedimensional structure of recombinant human osteogenic protein 1: structural paradigm for the transforming growth factor beta superfamily. Proceedings of the National Academy of Sciences, 93(2), pp.878883. 
Galloway, S., McNatty, K., Cambridge, L., Laitinen, M., Juengel, J., \& Jokiranta, T. et al. (2000). Mutations in an oocyte-derived growth factor gene (BMP15) cause increased ovulation rate and infertility in a dosage-sensitive manner. Nature Genetics, 25, 279 - 283. http://dx.doi.org/doi:10.1038/77033

Hanrahan, J., Gregan, S., Muslant, P., Mullen, M., Davis, G., Powell, R., \& Galloway, S. (2004). Mutations in the Genes for Oocyte-Derived Growth Factors GDF9 and BMP15 Are Associated with Both Increased Ovulation Rate and Sterility in Cambridge and Belclare Sheep (Ovis aries). Biology of Reproduction, 70(4), 900-909. http://dx.doi.org/10.1095/biolreprod.103.023093

Hayashi, M., McGee, E., Min, G., Klein, C., Rose, U., Duin, M., \& Hsueh, A. (1999). Recombinant Growth Differentiation Factor-9 (GDF-9) Enhances Growth and Differentiation of Cultured Early Ovarian Follicles

1. Endocrinology, 140(3), 1236-1244. http://dx.doi.org/10.1210/endo.140.3.6548

Hsueh, A., McGee, E., Hayashi, M., \& Hsu, S. (2000). Hormonal regulation of early follicle development in the rat ovary. Molecular And Cellular Endocrinology, 163(1-2), 95-100. http://dx.doi.org/10.1016/s03037207(99)00245-2

Hussein, T., Thompson, J. and Gilchrist, R. (2006). Oocyte-secreted factors enhance oocyte developmental competence. Developmental Biology, 296(2), pp.514-521.

Ioannou, Y., Zeidner, K., Grace, M., \& Desnick, R. (1998). Human $\alpha$-galactosidase A: glycosylation site 3 is essential for enzyme solubility. Biochem. J., 332(3), 789-797. http://dx.doi.org/10.1042/bj3320789

Jakowlew, S., Dillard, P., Kondaiah, P., Sporn, M. and Roberts, A. (1988). SEQUENCES OF INTEREST: Complementary Deoxyribonucleic Acid Cloning of a Novel Transforming Growth Factor- $\beta$ Messenger Ribonucleic Acid from Chick Embryo Chondrocytes. Molecular Endocrinology, 2(8), pp.747-755.

Johnson, P., Dickens, M., Kent, T., \& Giles, J. (2005). Expression and Function of Growth Differentiation Factor-9 in an Oviparous Species, Gallus 
domesticus. Biology Of Reproduction,72(5), 1095-1100.

http://dx.doi.org/10.1095/biolreprod.104.036822

Johnstone, R., Andrew, S., Hogarth, M., Pietersz, G. and McKenzie, I. (1990). The effect of temperature on the binding kinetics and equilibrium constants of monoclonal antibodies to cell surface antigens. Molecular Immunology, 27(4), pp.327-333.

Juengel, J. and McNatty, K. (2005). The role of proteins of the transforming growth factor-superfamily in the intraovarian regulation of follicular development. Human Reproduction Update, 11(2), pp.144-161.

Juengel, J., Bodensteiner, K., Heath, D., Hudson, N., Moeller, C., Smith, P., Galloway, S., Davis, G., Sawyer, H. and McNatty, K. (2004). Physiology of GDF9 and BMP15 signalling molecules. Animal Reproduction Science, 82-83, pp.447460.

Juengel, J., Hudson, N., Heath, D., Smith, P., Reader, K., Lawrence, S., O'Connell, A., Laitinen, M., Cranfield, M., Groome, N., Ritvos, O. and McNatty, K. (2002). Growth Differentiation Factor 9 and Bone Morphogenetic Protein 15 Are Essential for Ovarian Follicular Development in Sheep. Biology of Reproduction, 67(6), pp.1777-1789.

Kawabata, M., Inoue, H., Hanyu, A., Imamura, T. and Miyazono, K. (1998). Smad proteins exist as monomers in vivo and undergo homo- and heterooligomerization upon activation by serine/threonine kinase receptors. The EMBO Journal, 17(14), pp.4056-4065.

Kurien, B. and Scofield, R. (2006). Western blotting. Methods, 38(4), pp.283-293.

Laitinen, M., Vuojolainen, K., Jaatinen, R., Ketola, I., Aaltonen, J., Lehtonen, E., Heikinheimo, M. and Ritvos, O. (1998). A novel growth differentiation factor9 (GDF-9) related factor is co-expressed with GDF-9 in mouse oocytes during folliculogenesis. Mechanisms of Development, 78(1-2), pp.135-140.

Lin, J., Pitman-Crawford, J., Bibby, A., Hudson, N., McIntosh, C., Juengel, J., \& McNatty, K. (2012). Effects of species differences on oocyte regulation of 
granulosa cell function. Reproduction, 144(5), 557-567.

http://dx.doi.org/10.1530/rep-12-0267

Lin, S., Lerch, T., Cook, R., Jardetzky, T., \& Woodruff, T. (2006). The structural basis of TGF-, bone morphogenetic protein, and activin ligand binding. Reproduction, 132(2), 179-190.

http://dx.doi.org/10.1530/rep.1.01072

Macias, M., Martin-Malpartida, P., \& Massagué, J. (2015). Structural determinants of Smad function in TGF- $\beta$ signaling. Trends In Biochemical Sciences, 40(6), 296-308. http://dx.doi.org/10.1016/j.tibs.2015.03.012

Martinez-Royo, A., Jurado, J., Smulders, J., Martí, J., Alabart, J., \& Roche, A. et al. (2008). A deletion in the bone morphogenetic protein 15 gene causes sterility and increased prolificacy in Rasa Aragonesa sheep. Animal Genetics, 39(3), 294-297. http://dx.doi.org/10.1111/j.13652052.2008.01707.x

Massagué, J. (2000). How cells read TGF- beta signals. Nature Reviews Molecular Cell Biolog, 1, pp.169-178.

Massagué, J. (2012). TGFß signalling in context. Nature Reviews Molecular Cell Biology, 13(10), 616-630. http://dx.doi.org/10.1038/nrm3434

McIntosh, C., Lun, S., Lawrence, S., Western, A., McNatty, K. and Juengel, J. (2008). The Proregion of Mouse BMP15 Regulates the Cooperative Interactions of BMP15 and GDF9. Biology of Reproduction, 79(5), pp.889-896.

McIntosh, C., Lawrence, S., Smith, P., Juengel, J. and McNatty, K. (2012). Active immunization against the proregions of GDF9 or BMP15 alters ovulation rate and litter size in mice. Reproduction, 143(2), pp.195-201.

McNatty, K., Reader, K., Smith, P., Heath, D. and Juengel, J. (2007). Control of ovarian follicular development to the gonadotrophin-dependent phase: a 2006 perspective. Reproduction in Domestic Ruminants, 6(1), pp.55-68.

McNatty, K., Juengel, J., Reader, K., Lun, S., Myllymaa, S., \& Lawrence, S. et al. (2005). Bone morphogenetic protein 15 and growth differentiation factor 9 co-operate to regulate granulosa cell function in ruminants. Reproduction, 129(4), 481-487. http://dx.doi.org/10.1530/rep.1.00517 
McPherron, A. \& Lee, S. (1993). GDF-3 and GDF-9: Two New Members of the Transforming Growth Factor- $\beta$ Superfamily Containing a Novel Pattern of Cysteines. The Journal of Biological Chemistry, 268(5), 3444-3449.

Miettinen, P. (1994). TGF-beta induced transdifferentiation of mammary epithelial cells to mesenchymal cells: involvement of type I receptors. The Journal of Cell Biology, 127(6), pp.2021-2036.

Monestier, O., Servin, B., Auclair, S., Bourquard, T., Poupon, A., Pascal, G., \& Fabre, S. (2014). Evolutionary Origin of Bone Morphogenetic Protein 15 and Growth and Differentiation Factor 9 and Differential Selective Pressure Between Mono- and Polyovulating Species. Biology Of Reproduction, 91(4), 83-83. http://dx.doi.org/10.1095/biolreprod.114.119735

Mottershead, D., Harrison, C., Mueller, T., Stanton, P., Gilchrist, R. and McNatty, K. (2013). Growth differentiation factor 9:bone morphogenetic protein 15 (GDF9:BMP15) synergism and protein heterodimerization. Proceedings of the National Academy of Sciences, 110(25), pp.E2257-E2257.

Mottershead, D., Ritter, L. and Gilchrist, R. (2012). Signalling pathways mediating specific synergistic interactions between GDF9 and BMP15. Molecular Human Reproduction, 18(3), pp.121-128.

Mottershead, D., Sugimura, S., Al-Musawi, S., Li, J., Richani, D., \& White, M. et al. (2015). Cumulin, an Oocyte-secreted Heterodimer of the Transforming Growth Factor- $\beta$ Family, Is a Potent Activator of Granulosa Cells and Improves Oocyte Quality. Journal Of Biological Chemistry,290 (39), 2400724020. http://dx.doi.org/10.1074/jbc.m115.671487

Mueller, T. \& Nickel, J. (2012). Promiscuity and specificity in BMP receptor activation. FEBS Letters,586(14), 1846-1859. http://dx.doi.org/10.1016/j.febslet.2012.02.043

Murphy, R. and Lamb, G. (2013). Important considerations for protein analyses using antibody based techniques: down-sizing Western blotting up-sizes outcomes. The Journal of Physiology, 591(23), pp.5823-5831.

Otsuka, F., McTavish, K. and Shimasaki, S. (2011). Integral role of GDF-9 and BMP-15 in ovarian function. Molecular Reproduction and Development, 78(1), pp.9-21. 
Ozkaynak, E., Rueger, D., Drier, E., Corbett, C., Ridge, R., Sampath, T. and Oppermann, H. (1990). OP-1 cDNA encodes an osteogenic protein in the TGF-b family. The EMBO Journal, 9(7), pp.2085-2093.

Peng, J., Li, Q., Wigglesworth, K., Rangarajan, A., Kattamuri, C., Peterson, R., Eppig, J., Thompson, T. and Matzuk, M. (2013). Growth differentiation factor 9:bone morphogenetic protein 15 heterodimers are potent regulators of ovarian functions. Proceedings of the National Academy of Sciences, 110(8), pp.E776E785.

Reader, K., Heath, D., Lun, S., McIntosh, C., Western, A., Littlejohn, R., McNatty, K. and Juengel, J. (2012). Signalling pathways involved in the cooperative effects of ovine and murine GDF9+BMP15-stimulated thymidine uptake by rat granulosa cells. Reproduction, 142(1), pp.123-131.

Shi, M., Zhu, J., Wang, R., Chen, X., Mi, L., Walz, T. and Springer, T. (2011). Latent TGF- $\beta$ structure and activation. Nature, 474(7351), pp.343-349.

Shimasaki, S., Moore, R., Otsuka, F. and Erickson, G. (2004). The Bone Morphogenetic Protein System In Mammalian Reproduction. Endocrine Reviews, 25(1), pp.72-101.

Simpson, C., Stanton, P., Walton, K., Chan, K., Ritter, L., Gilchrist, R., \& Harrison, C. (2012). Activation of Latent Human GDF9 by a Single Residue Change (Gly 391 Arg) in the Mature Domain. Endocrinology, 153(3), 1301-1310. http://dx.doi.org/10.1210/en.2011-1632

Su, Y., Wu, X., O'Brien, M., Pendola, F., Denegre, J., Matzuk, M. and Eppig, J. (2004). Synergistic roles of BMP15 and GDF9 in the development and function of the oocyte-cumulus cell complex in mice: genetic evidence for an oocytegranulosa cell regulatory loop. Developmental Biology, 276(1), pp.64-73.

Taylor, S. and Posch, A. (2014). The Design of a Quantitative Western Blot Experiment. BioMed Research International, 2014, pp.1-8.

Ulloa, L., Doody, J. and Massagué, J. (1999). Inhibition of transforming growth factor-/SMAD signalling by the interferon- 8/STAT pathway. Nature, 397, pp.710-713. 
Wrana, J., Attisano, L., Cárcamo, J., Zentella, A., Doody, J., Laiho, M., Wang, X. and Massague, J. (1992). TGF $\beta$ signals through a heteromeric protein kinase receptor complex. Cell, 71(6), pp.1003-1014.

Yan, C., Wang, P., DeMayo, J., DeMayo, F., Elvin, J., \& Carino, C. et al. (2001). Synergistic Roles of Bone Morphogenetic Protein 15 and Growth Differentiation Factor 9 in Ovarian Function.Molecular Endocrinology, 15(6), 854-866. http://dx.doi.org/10.1210/mend.15.6.0662

Yeo, C., Gilchrist, R., Thompson, J., \& Lane, M. (2007). Exogenous growth differentiation factor 9 in oocyte maturation media enhances subsequent embryo development and fetal viability in mice. Human Reproduction, 23(1), 67-73. http://dx.doi.org/10.1093/humrep/dem140

Yu, L. (2002). TGF-beta receptor-activated p38 MAP kinase mediates Smadindependent TGF-beta responses. The EMBO Journal, 21(14), pp.3749-3759 


\section{Appendices}

\section{Appendix I: Recipes}

All the chemicals used and purchased are indicated in Appendix II.

\section{$1.10 .9 \%$ Saline solution}

To prepare a $0.9 \%$ saline solution, $9 \mathrm{~g}$ of $\mathrm{NaCl}$ was dissolved in $\mathrm{dH}_{2} \mathrm{O}$ to give a final volume of $1 \mathrm{~L}$. Then, the solution was aliquoted into $500 \mathrm{~mL}$ glass bottles and autoclaved to be stored at room temperature for up to 1 month.

\section{$1.270 \%$ ethanol}

To prepare $70 \%$ ethanol, $700 \mathrm{~mL}$ of absolute, molecular biology grade ethanol was added to $300 \mathrm{~mL}$ of $\mathrm{dH}_{2} \mathrm{O}$.

\subsection{The extraction media}

A pack of M199 and $47.6 \mathrm{~g}$ of HEPES ultrapure is dissolved in $500 \mathrm{~mL}$ of $\mathrm{dH}_{2} \mathrm{O}$. Then, the solution is adjusted by $\mathrm{NaOH}$ to reach $\mathrm{pH}$ 7.3. Later, the solution is made up to $1 \mathrm{~L}$ and filter sterilised into the bottles. Then, $10 \mathrm{~mL}$ of PenicillinStreptomycin (PS) is added. Finally, osmolality is tested, which should range between 280-300 Os. The solution is keep refrigerated.

\subsection{Incubation media}

To prepare incubation media, $500 \mathrm{~mL}$ of sterile water was added to M199 powder (M5017; Sigma Aldrich) containing Earle's Salt's, L-glutamine, and 2.2 $\mathrm{g} / \mathrm{L}$ sodium bicarbonate and stored at $4^{\circ} \mathrm{C}$. Prior to usage, penicillinstreptamycin was added at a final concentration of 100IU/mL (100 units/mL of penicillin and $100 \mu \mathrm{g} / \mathrm{mL}$ of streptomycin) and a $15 \mathrm{~mL}$ aliquot was prepared under aseptic conditions. The media was stored at $4^{\circ} \mathrm{C}$ for no longer than 1 month.

\section{$1.510 x$ Protease inhibitor}

One tablet of Complete EDTA free protease inhibitor cocktail (04693159001;

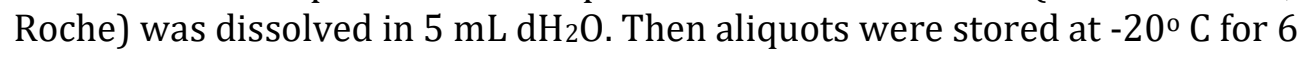
months. Prior to use, aliquots were defrosted and kept at $4^{\circ} \mathrm{C}$ and used within two weeks.

\subsection{Separating gel}

The following table includes the chemical compounds that were used to prepare a $13.5 \%$ separating gel. 


\begin{tabular}{|c|c|}
\hline Milli Q water & $2.85 \mathrm{~mL}$ \\
\hline $1.5 \mathrm{M}$ Tris-HCl pH 8.8 & $2.5 \mathrm{~mL}$ \\
\hline $10 \%(\mathrm{w} / \mathrm{v})$ SDS & $0.1 \mathrm{~mL}$ \\
\hline Bis-acrylamide mix $(30 \%)$ & $4.5 \mathrm{~mL}$ \\
\hline $10 \%$ (w/v) ammonium persulphate & $50 \mu \mathrm{L}$ \\
\hline TEMED & $5 \mu \mathrm{L}$ \\
\hline
\end{tabular}

\subsection{Stacking gel}

The following table includes the chemical compounds that were used to prepare a stacking gel.

\begin{tabular}{|c|c|}
\hline Milli Q water & $3.05 \mathrm{~mL}$ \\
\hline $0.5 \mathrm{M}$ Tris-HCl pH 6.8 & $1.25 \mathrm{~mL}$ \\
\hline $10 \%(\mathrm{w} / \mathrm{v})$ SDS & $50 \mu \mathrm{L}$ \\
\hline Bis-acrylamide mix $(30 \%)$ & $0.65 \mathrm{~mL}$ \\
\hline $10 \%(\mathrm{w} / \mathrm{v})$ ammonium persulphate & $25 \mu \mathrm{L}$ \\
\hline TEMED & $5 \mu \mathrm{L}$ \\
\hline
\end{tabular}

\subsection{2x Non-reducing sample buffer}

The following table includes the chemical compounds that were used to prepare the non-reducing sample buffer. The mixture then was then aliquoted into smaller amounts and stored at $-20^{\circ} \mathrm{C}$ for up to 3 months.

\begin{tabular}{|c|c|}
\hline Milli Q water & $4.5 \mathrm{~mL}$ \\
\hline $0.5 \mathrm{M}$ Tris-HCl pH 6.8 & $1.0 \mathrm{~mL}$ \\
\hline $10 \%$ (w/v) SDS & $4.6 \mathrm{~mL}$ \\
\hline Glycerol & $4.5 \mathrm{~mL}$ \\
\hline $1.0 \%(\mathrm{w} / \mathrm{v})$ bromophenol blue & $0.4 \mathrm{~mL}$ \\
\hline
\end{tabular}

\section{$1.92 x$ Reducing sample buffer}

The following table includes the chemical compounds that were used to prepare the reducing sample buffer. The mixture then was aliquoted into smaller amounts and stored at $-20^{\circ} \mathrm{C}$ up to 3 months.

\begin{tabular}{|c|c|}
\hline Milli Q water & $4.5 \mathrm{~mL}$ \\
\hline $0.5 \mathrm{M}$ Tris-HCl pH 6.8 & $1.0 \mathrm{~mL}$ \\
\hline 10\% (w/v) SDS & $4.6 \mathrm{~mL}$ \\
\hline Glycerol & $4.5 \mathrm{~mL}$ \\
\hline 1.0\% (w/v) bromophenol blue & $0.4 \mathrm{~mL}$ \\
\hline Dithiothreitol (DTT) & $80 \mathrm{mg}$ \\
\hline$\beta$-mercaptoethanol (added fresh) & $1.66 \mathrm{~mL}$ \\
\hline
\end{tabular}




\section{$1.105 x$ running buffer}

To prepare a $5 \mathrm{x}$ running buffer, $360 \mathrm{~g}$ of glycine, $75 \mathrm{~g}$ of Tris-base and $25 \mathrm{~g}$ of sodium dodecyl sulfate (SDS) were dissolved in distilled water to a final volume of $5 \mathrm{~L}$.

\subsection{0x Tris-gylcine stock}

To prepare a 10x Tris-glycine stock, $30.3 \mathrm{~g}$ of Tris-base and $144 \mathrm{~g}$ of glycine were dissolved in distilled water to make a final volume of $1 \mathrm{~L}$.

\subsection{Transfer buffer}

To prepare the transfer buffer, $200 \mathrm{~mL}$ of $10 \mathrm{x}$ Tris-glycine stock and $400 \mathrm{~mL}$ of methanol were added to $1400 \mathrm{~mL}$ of distilled water to make a final volume of $2 \mathrm{~L}$. This solution was pre-chilled before use.

\subsection{Membrane washing buffer}

To prepare the membrane washing buffer, $20 \mathrm{~mL}$ of $1 \mathrm{M}$ Tris- $\mathrm{HCl}(\mathrm{pH} 7.5), 8.76 \mathrm{~g}$ of sodium chloride $(\mathrm{NaCl})$, and $1 \mathrm{~mL}$ of Tween 20 were added to distilled water to make a final volume of $1 \mathrm{~L}$.

\section{$1.145 \%$ blocking buffer}

To prepare a $5 \%$ blocking buffer, $2.5 \mathrm{~g}$ of trim milk powder was dissolved in 50 mL of membrane washing buffer.

\subsection{Stripping buffer}

To prepare $100 \mathrm{~mL}$ of stripping buffer, $20 \mathrm{~mL}$ of $10 \%$ aqueous SDS solution, 12.5 $\mathrm{mL}$ of $0.5 \mathrm{M}$ Tris-HCl (pH 6.8), $0.7 \mathrm{~mL}$ of $\beta$-mercaptoethanol and $66.8 \mathrm{~mL}$ of distilled water were mixed in a sealable Klip It ${ }^{\mathrm{TM}}$ container (Sistema). The stripping buffer was made fresh prior use.

\subsection{Cell culture medium}

A premade solution of $500 \mathrm{~mL}$ of Mc'Coy's 5A modified medium (16600082; Gibco) was purchased and stored at $4^{\circ} \mathrm{C}$. Upon opening, penicillin-streptamycin was added at a final concentration of $100 \mathrm{IU} / \mathrm{mL}$ and $1.1 \mathrm{~g}$ of sodium bicarbonate was added. $50 \mathrm{~mL}$ of this media, with the addition of polyvinyl alcohol (PVA) at a final concentration of $0.01 \%$ was warmed up before usage. The preparation of media was performed under aseptic conditions in a biohazard hood. Media was stored at $4^{\circ} \mathrm{C}$ and was used within 1 month. 
Appendix II: Chemicals

\begin{tabular}{|c|c|c|}
\hline Chemical Name & Lot/Cat number & Company \\
\hline Ammonium persulphate & $161-07000$ & BioRad, USA California \\
\hline $\begin{array}{c}\text { Bromophenol blue } \\
\text { sodium salt }\end{array}$ & B8026 & Sigma-Aldrich \\
\hline $\begin{array}{l}\text { Bissulfosuccinimidyl } \\
\text { suberate (BS3) }\end{array}$ & 21580 & $\begin{array}{c}\text { Thermo Scientific, USA, } \\
\text { IL }\end{array}$ \\
\hline $\begin{array}{l}\text { Complete EDTA-free } \\
\text { Protease inhibitor } \\
\text { cocktail tablets }\end{array}$ & 04693159001 & Roche \\
\hline $\begin{array}{l}\text { Dithiothreitol (DTT)- } \\
\text { Electrophoresis Purity }\end{array}$ & 1610611 & Bio-Rad \\
\hline Ethanol & ALK0124 & ANDREW \\
\hline Glycerol & K32056060 325 & $\begin{array}{c}\text { BDH laboratory supplies; } \\
\text { UK, Poole Dorset }\end{array}$ \\
\hline Glycine & $2 A 002393$ & AppliChem \\
\hline $\begin{array}{c}\text { HEPES (4-(2- } \\
\text { hydroxyethyl)-1- } \\
\text { piperazineethanesulfonic } \\
\text { acid ) Ultrapure }\end{array}$ & 11344041 & Life Technologies \\
\hline Luminol & MKBJ0761V & SIGMA \\
\hline $\begin{array}{c}\text { Mc'Coy's 5A modified } \\
\text { Medium }\end{array}$ & 16600082 & $\begin{array}{c}\text { Gibco (Thermo Fisher } \\
\text { Scientific) }\end{array}$ \\
\hline $\begin{array}{c}\text { Medium } 199500 \mathrm{~mL}+ \\
\text { Earle's Salt's+ L- } \\
\text { Glutamin+ } 2.2 \mathrm{~g} / \mathrm{L} \\
\text { Bicarbonate }\end{array}$ & 11150059 & $\begin{array}{c}\text { Gibco (Thermo Fisher } \\
\text { Scientific) }\end{array}$ \\
\hline $\begin{array}{l}\text { Medium 199, powder- } \\
\text { M5017+ Earle's Salt's+ L- } \\
\text { Glutamin }\end{array}$ & M5017 & Sigma Aldrich \\
\hline Methanol & ME03162500 & $\begin{array}{l}\text { Scharlau; Spain, } \\
\text { Barcelona }\end{array}$ \\
\hline $\begin{array}{l}\text { PhosphateBuffered } \\
\text { Saline (PBS) }\end{array}$ & 10010023 & Life Technologies \\
\hline Penicillin-Streptomycin & 15140122 & $\begin{array}{c}\text { Gibco (Thermo Fisher } \\
\text { Scientific) }\end{array}$ \\
\hline p-Coumeric acid & 017K1468 & SIGMA \\
\hline Polyvinyl Alcohol (PVA) & P8136-250G & SIGMA \\
\hline Sodium Bicarbonate & SLBF0769V & Sigma Aldrich \\
\hline $\begin{array}{c}\text { Sodium Dodecyl Sulfate } \\
\text { (SDS) }\end{array}$ & 115377 & $\begin{array}{c}\text { Fisher Chemical; USA, } \\
\text { Pittsburgh }\end{array}$ \\
\hline
\end{tabular}




\begin{tabular}{|c|c|c|}
\hline Sodium Chloride & 1333838 & $\begin{array}{c}\text { Fisher Chemical; USA, } \\
\text { Pittsburgh }\end{array}$ \\
\hline TEMED & $161-0800$ & BioRad; USA, California \\
\hline Tris-Ultrapure & 2 A002393 & AppliChem \\
\hline Tween $^{\circledR} 20$ & 115125 & $\begin{array}{c}\text { Fisher Scientific; USA, } \\
\text { Pittsburgh }\end{array}$ \\
\hline $\begin{array}{c}\text { 2-Mercaptoethanol }(\beta- \\
\text { mercaptoethanol) }\end{array}$ & $46496 \mathrm{KMV}$ & SIGMA \\
\hline $\begin{array}{c}30 \% \text { Acrylamide/Bis } \\
\text { Solution }\end{array}$ & $161-0158$ & BioRad; USA, California \\
\hline
\end{tabular}


Appendix III: Antibodies

\begin{tabular}{|c|c|c|c|c|}
\hline Antibody & $\begin{array}{c}\text { Lot } \\
\text { number }\end{array}$ & Target Sequence & $\begin{array}{c}\text { Storage } \\
\text { conditions }\end{array}$ & Source \\
\hline $\begin{array}{l}\text { HRP- } \\
\text { conjugated } \\
\text { antibody } \\
\text { Rabbit Anti- } \\
\text { mouse IgG }\end{array}$ & 119936 & $\begin{array}{l}\text { Reacts with whole } \\
\text { molecule mouse IgG } \\
\text { and the light chains of } \\
\text { other mouse } \\
\text { immunoglobulins }\end{array}$ & $\begin{array}{c}-20^{\circ} \mathrm{C} \text { at } \\
0.4 \mathrm{mg} / \mathrm{mL} \\
\text { in equal } \\
\text { parts High- } \\
\text { Q water } \\
\text { and } \\
\text { glycerol }\end{array}$ & $\begin{array}{c}\text { Jackson } \\
\text { ImmunoResearch } \\
\text { Laboratories Inc. }\end{array}$ \\
\hline $\begin{array}{l}\text { MAB37A } \\
\text { Anti GDF9 }\end{array}$ & $\mathrm{N} / \mathrm{A}$ & $\begin{array}{l}\text { DQESASSELKKPLV( } \underline{C}) \\
\text { sequence towards the } \\
\text { N-terminal of the } \\
\text { mature ovine GDF9. } \\
\text { The underlined } \\
\text { cysteine residue used } \\
\text { to chemically } \\
\text { conjugate sequence to } \\
\text { KLH. }\end{array}$ & $\begin{array}{l}4^{\circ} \mathrm{C} \text { in } \\
\mathrm{PBS} / 0.1 \% \\
\text { sodium } \\
\text { azide }\end{array}$ & $\begin{array}{l}\text { Oxford Brookes } \\
\text { University in the } \\
\text { United Kingdom } \\
\text { under contract to } \\
\text { AgResearch }\end{array}$ \\
\hline $\begin{array}{l}\text { MAB37G } \\
\text { Anti GDF9 }\end{array}$ & $\mathrm{N} / \mathrm{A}$ & $\begin{array}{l}\text { SELLKKPLVPASVNLS( }(\underline{\mathrm{C}}) \\
\text { sequence towards the } \\
\text { N-terminal of the } \\
\text { mature ovine GDF9. } \\
\text { The underlined } \\
\text { cysteine residue used } \\
\text { to chemically } \\
\text { conjugate sequence to } \\
\text { KLH. }\end{array}$ & $\begin{array}{l}4^{\circ} \mathrm{C} \text { in } \\
\text { PBS } / 0.1 \% \\
\text { sodium } \\
\text { azide }\end{array}$ & $\begin{array}{c}\text { GenScript }{ }^{\circledR}, \text { USA } \\
\text { under contract to } \\
\text { Victoria } \\
\text { University of } \\
\text { Wellington }\end{array}$ \\
\hline $\begin{array}{l}\text { MAB61A } \\
\text { Anti BMP15 }\end{array}$ & $\mathrm{N} / \mathrm{A}$ & $\begin{array}{l}\text { SEVPGPSREHDGPES } \\
\text { sequence towards the } \\
\text { N-terminal of the } \\
\text { mature ovine BMP15. }\end{array}$ & $\begin{array}{l}4^{\circ} \mathrm{C} \text { in } \\
\mathrm{PBS} / 0.1 \% \\
\text { sodium } \\
\text { azide }\end{array}$ & $\begin{array}{c}\text { Oxford Brookes } \\
\text { University in the } \\
\text { United Kingdom } \\
\text { under contract to } \\
\text { AgResearch }\end{array}$ \\
\hline $\begin{array}{l}\text { MAB61B } \\
\text { Anti BMP15 }\end{array}$ & $\mathrm{N} / \mathrm{A}$ & $\begin{array}{l}\text { QAGSIASEVPGPSR( }(\underline{\mathrm{C}}) \\
\text { sequence towards the } \\
\text { N-terminal of the } \\
\text { mature ovine BMP15. } \\
\text { The underlined } \\
\text { cysteine residue used } \\
\text { to chemically } \\
\text { conjugate sequence to } \\
\text { KLH. }\end{array}$ & $\begin{array}{l}4^{\circ} \mathrm{C} \text { in } \\
\mathrm{PBS} / 0.1 \% \\
\text { sodium } \\
\text { azide }\end{array}$ & $\begin{array}{c}\text { GenScript }{ }^{\circledR}, \text { USA } \\
\text { under contract to } \\
\text { Victoria } \\
\text { University of } \\
\text { Wellington }\end{array}$ \\
\hline
\end{tabular}

